\title{
Damage-Associated Molecular Patterns Modulation by microRNA: Relevance on Immunogenic Cell Death and Cancer Treatment Outcome
}

\author{
María Julia Lamberti ${ }^{1,2, * \mathbb{D}}$, Annunziata Nigro ${ }^{2}$, Vincenzo Casolaro ${ }^{2} \mathbb{D}$, Natalia Belén Rumie Vittar $^{1}$ and \\ Jessica Dal Col ${ }^{2, *(D)}$ \\ 1 INBIAS, CONICET-UNRC, Río Cuarto, Córdoba 5800, Argentina; nrumievittar@exa.unrc.edu.ar \\ 2 Department of Medicine, Surgery and Dentistry 'Scuola Medica Salernitana', University of Salerno, Baronissi, \\ 84081 Salerno, Italy; annnigro@unisa.it (A.N.); vcasolaro@unisa.it (V.C.) \\ * Correspondence: mlamberti@exa.unrc.edu.ar (M.J.L.); jdalcol@unisa.it (J.D.C.)
}

check for

updates

Citation: Lamberti, M.J.; Nigro, A.; Casolaro, V.; Rumie Vittar, N.B.; Dal Col, J. Damage-Associated Molecular Patterns Modulation by microRNA: Relevance on Immunogenic Cell Death and Cancer Treatment Outcome. Cancers 2021, 13, 2566. https://doi.org/10.3390/

cancers13112566

Academic Editor: Vita Golubovskaya

Received: 1 April 2021

Accepted: 18 May 2021

Published: 24 May 2021

Publisher's Note: MDPI stays neutral with regard to jurisdictional claims in published maps and institutional affiliations.

Copyright: (c) 2021 by the authors. Licensee MDPI, Basel, Switzerland. This article is an open access article distributed under the terms and conditions of the Creative Commons Attribution (CC BY) license (https:// creativecommons.org/licenses/by/ $4.0 /)$.
Simple Summary: Inside the cell, damage-associated molecular pattern molecules (DAMPs) play several physiological functions, but when they are released or translocated to the extracellular space, they gain additional immunogenic roles. Thus, DAMPs are considered key hallmarks of immunogenic cell death (ICD) in cancer, a functionally unique regulated form of stress-mediated cell death that activates the immune system response against tumor cells. Several epigenetic modulators of DAMPs have been reported. In this review, we aimed to provide an overview of the effects of microRNAs (miRNAs) on the expression of DAMPs and the putative link between miRNA, DAMPs, and cell death, focused on ICD. Overall, we propose that miRNAs, by targeting DAMPs, play critical roles in the regulation of both cell death and immune-associated mechanisms in cancer, while evidence of their potential involvement in ICD is limited. Finally, we discuss emerging data regarding the impact of miRNAs' modulation on cancer treatment outcome.

Abstract: Immunogenic cell death (ICD) in cancer is a functionally unique regulated form of stressmediated cell death that activates both the innate and adaptive immune response against tumor cells. ICD makes dying cancer cells immunogenic by improving both antigenicity and adjuvanticity. The latter relies on the spatiotemporally coordinated release or exposure of danger signals (DAMPs) that drive robust antigen-presenting cell activation. The expression of DAMPs is often constitutive in tumor cells, but it is the initiating stressor, called ICD-inducer, which finally triggers the intracellular response that determines the kinetics and intensity of their release. However, the contribution of cell-autonomous features, such as the epigenetic background, to the development of ICD has not been addressed in sufficient depth. In this context, it has been revealed that several microRNAs (miRNAs), besides acting as tumor promoters or suppressors, can control the ICD-associated exposure of some DAMPs and their basal expression in cancer. Here, we provide a general overview of the dysregulation of cancer-associated miRNAs whose targets are DAMPs, through which new molecular mediators that underlie the immunogenicity of ICD were identified. The current status of miRNAtargeted therapeutics combined with ICD inducers is discussed. A solid comprehension of these processes will provide a framework to evaluate miRNA targets for cancer immunotherapy.

Keywords: miRNA; immunogenic cell death; cancer

\section{Introduction}

Under physiological homeostasis, cell death involved in the continuous cellular turnover is non-immunogenic or even tolerogenic. This silence mechanism is imperative given that the activation of an immune response against dead cell-associated antigens would have autoimmune-related catastrophic consequences [1]. On the other hand, the death of infected or tumor cells under specific treatment conditions can elicit a robust antigen-specific immune 
response. This type of death that enhances the immunogenic potential of dying cells has been termed since 2005 as Immunogenic Cell Death (ICD) [2,3]. In the context of cancer therapies, several chemotherapeutics (doxorubicin, cisplatin, oxaliplatin), radiotherapy, oncolytic virus therapy, and photodynamic therapy have been characterized as ICD-inducers [4]. Innate and adaptive immune responses elicited by such anti-cancer agents are now deemed essential for an optimal therapeutic outcome, highlighting the clinical relevance of ICD.

Formerly, ICD was exclusively described in terms of immunogenic extrinsic or intrinsic apoptosis, but recently, with the increasing knowledge of cell death mechanisms, many non-apoptotic cell death processes have been involved in immune activation, including necroptosis, pyroptosis, and ferroptosis [5]. However, ICD cannot be considered only as a cellular death event given its strong dependence on the complex cellular communication between dying and immune cells [6]. In fact, for ICD to be successfully promoted, an exact combination of damage-associated molecular patterns (DAMPs) must be released/exposed in a spatiotemporally coordinated sequence and recognized by immune cells [7]. DAMPs are molecules that exert intracellular physiological functions, but gain additional immunogenic properties when they are exposed to the extracellular environment. Thanks to this peculiarity, DAMPs have been defined as ICD hallmarks. In this context, the immunogenicity of dying tumor cells is dependent on two main factors: antigenicity (conferred by tumor-associated antigens, cancer-testis antigen, and/or neo-epitopes) and adjuvanticity (provided by DAMPs) $[8,9]$. Accordingly, the inhibition of various processes involved in DAMPs' expression, emission, and sensing could support the neoplastic cell full escape from immune recognition and elimination and potentiate malignant lethal progression.

Interestingly, several epigenetic modulators that suppress or activate genes encoding ICD-associated DAMPs have been discovered. They cause variations in gene expression through chromatin remodeling mechanisms, for example, DNA methylation and histone modification, and the generation of non-coding RNAs (ncRNAs), including long noncoding RNAs (lncRNAs), circular RNAs (circRNAs), and microRNAs (miRNAs) [10].

A recent review from Cruickshank et al. [8] recapitulated the evidence linking epigenetic modifications and ICD. In this review, our efforts are focused on extending that previous work by providing an overview of the current knowledge of miRNAs targeting ICD hallmarks and, thus, their potential involvement in ICD regulation and outcomes. We present a summary of the known miRNAs involved in DAMP modulation within tumors. Finally, we contextualize these findings in the design of novel therapeutic strategies.

Accumulating evidence indicates that several miRNAs can act as oncogenes (here termed oncomiRNAs) or tumor suppressor miRNAs by directly targeting different DAMPs, whose expression is frequently altered across human cancers. These observations lead us to forming the initial hypothesis that reestablishing the normal regulation of DAMP expression would constitute an important and clinically relevant goal to restore immunogenicity and to counteract immune evasion, which often results in the acquisition of chemoresistance and in tumor progression. However, as often happens in biological processes, the same molecules can perform completely different functions depending on the spatiotemporal context and/or the stimuli/insults to which the cell is subjected. Hence, DAMPs can both suppress cell death and promote the immunogenicity of cancer cells, according to tumor microenvironmental conditions. Therefore, we aimed here to provide a comprehensive and exhaustive overview of the effects of miRNAs on the expression of DAMPs, to help identify commonalities and differences that indicate possible interrelationships between miRNA, DAMPs, and cell death, with a special focus on ICD.

\section{Immunogenic Cell Death}

According to current models, cells undergoing ICD release or expose DAMPs on their surface can function as adjuvants for the innate immune system activation [9]. Most of these molecules have primarily non-immunological roles in the intracellular compartment before their mobilization by ICD. The adequate immunogenic response relies on the ability 
of specific stimuli to damage cells lethally while inducing the spatiotemporally coordinated emission of those DAMPs [11].

At the very beginning of the well-described ICD sequence, in a pre-apoptotic stage, the endoplasmic reticulum (ER) chaperone calreticulin (CRT) is translocated to the membrane before the cells exhibit phosphatidylserine residues [12]. Ecto-CRT mobilization works as an immunogenic "eat-me" signal for dendritic cells (DCs). This step is essential for an appropriate induction of ICD [12,13]. ICD also involves autophagy for optimal ATP active secretion. This autophagy-dependent release of ATP requires accumulation of ATP in autolysosomes [14]. In the extracellular space, ATP acts as a "find-me" signal for DCs and the consequent activation of the inflammasome to promote the release of the proinflammatory cytokine, interleukin (IL)-1 $\beta[15,16]$. Doxorubicin [17] and PDT-treated cancer cells [18] also upregulate a type I interferon (IFN-1) signaling cascade resulting in C-X-C motif chemokine ligand 10 (CXCL10) secretion and finally in DC maturation. Although they are usually located inside the cells, heat shock proteins 70 and 90 (Hsp70 and Hsp90), under ICD, can be expressed at the surface of the cell membrane or released in the extracellular microenvironment and participate in immune stimulation [11,19]. In the late stages of apoptosis, high-mobility group box 1 (HMGB1) is passively released and binds Toll-Like Receptor 4 (TLR4) on DCs to increase antigen presentation [20].

The main objective of inducing ICD is to overcome the immunosuppressive phenotype of the tumor microenvironment through the restitution of the three signals between DC-T cell interaction, all of them mandatory for immunogenic $\mathrm{T}$ cell activation: (a) signal 1: antigen presentation; (b) signal 2: co-stimulation; and (c) signal 3: production of stimulatory cytokines [21]. Along this process, DCs engulf fragments of the stressed/dying cell and incorporate antigenic peptides into MHCs (antigenicity). During antigen presentation, the maturation signals triggered by DAMPs (adjuvanticity) lead to optimal activation of T cells, which finally detect and eliminate cancer cells in a highly precise, antigen-specific fashion [22] (Figure 1).

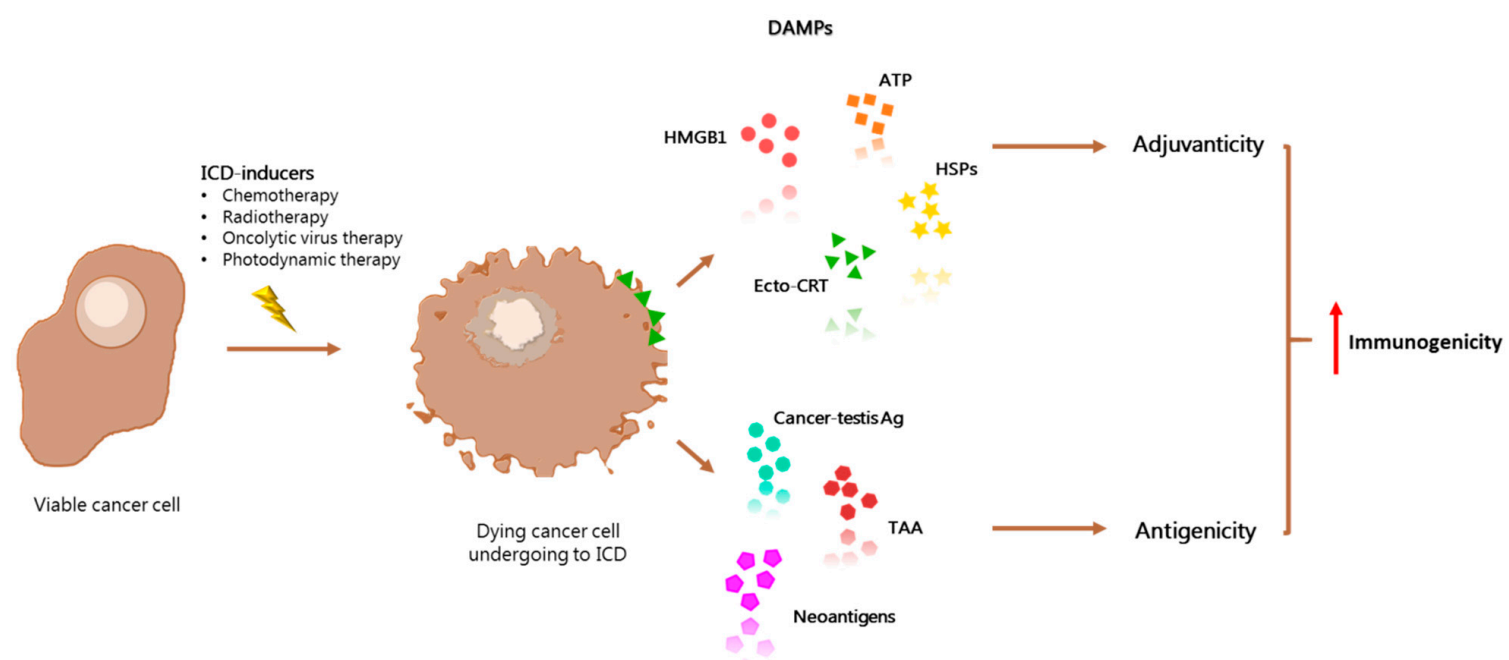

Figure 1. ICD-antitumor effect relies on the enhancement of adjuvanticity and antigenicity of tumor cells. In the tumor microenvironment, immunogenic cell death (ICD) triggered by several ICD-inducers plays a major role in stimulating antitumor immune response. Its lethal action leads to the release of tumor associated antigens (TAAs), cancer testis antigens, and neoantigens, which ultimately increases antigenicity. The concomitant exposure of damage-associated molecular patterns (DAMPs), such as ATP, calreticulin (CRT), HMGB1, and Hsps (Hsp70, Hsp90), confers a robust adjuvanticity to dying cancer cells. Both antigenicity and adjuvanticity enhancement leads to an exacerbated immunogenicity of ICD-undergoing tumor cells.

Linking the immunogenic potential of ICD with an immunotherapy regimen is a promising approach for antitumor treatment. In this sense, we have recently summarized the findings suggesting the use of ICD as a strategy to optimize the current vaccine design for cancer immunotherapy $[4,23]$. Unfortunately, immunosuppression exerted by the 
tumor microenvironment limits the potential success of this strategy. In line with these observations, we propose here to identify which immune-activating or immunosuppressive ICD hallmarks are epigenetically targeted by miRNAs.

\section{Epigenetic Regulation by miRNA}

Over the last years, many studies have been conducted that support the idea that genetic information can be tightly regulated by non-coding RNAs (ncRNAs). ncRNAs do not code for proteins, and can be classified into long non-coding RNAs (lncRNAs), circular RNAs (circRNAs), and microRNAs (miRNAs). Among these ncRNAs, here we focus on post-transcriptional regulation of the expression of ICD molecular mediators by miRNAs.

The main function of miRNAs is to repress protein production, working as posttranscriptional regulators of mRNA. The miRNA biogenesis initiates with the generation of a large primary transcript (pri-miRNA), mainly transcribed by RNA polymerase II, which is $5^{\prime}$ capped and $3^{\prime}$ polyadenylated. The pri-miRNAs are then cleaved into precursor miRNAs (pre-miRNAs) that consist of around 85 nucleotides exhibiting a stem-loop structure. This cleavage is made by a microprocessor complex, composed of the RNA-binding protein DGCR8 and the type III RNase Drosha. Pre-miRNAs are then transported from the nucleus to cytoplasm by the Ran/GTP/Exportin 5 complex, where they are processed by another RNase III enzyme, Dicer, to a 20-22-nucleotide miRNA:miRNA* duplex. The * denotes the passenger strand, which is degraded, while the other complementary strand is the mature or guide strand. The mature/guided miRNA is then incorporated into a protein complex termed RNA-induced silencing complex (RISC) and guides RISC to target mRNA. miRNAs exert their effects by complementary base-pair binding to a short 7-8 nucleotide "seed" region typically located in the $3^{\prime}$ untranslated region (UTR) of the mRNA that they inhibit [24]. Importantly, one miRNA may regulate many targeted genes, while one gene may be targeted by many miRNAs [25].

Nowadays, it is well known that transcriptional control changes, chromosomal abnormalities, epigenetic changes, and defects in the miRNA biogenesis machinery may lead to an aberrant miRNA expression in human cancers. It has been described that this dysregulation affects one or more of the hallmarks of cancer described by Hanahan and Weinberg [26]. Thus, in a cancer context, depending on their target genes and the environmental conditions, miRNAs could function as either oncogenes (termed here oncomiRNAs) or tumor suppressors [27].

Current evidence sheds more light on the functional properties of miRNAs and opens new paradigms that need to be further explored [25]. In this sense, it has been demonstrated that miRNAs can act in different cellular locations (cytoplasm, mitochondrion, nucleus, and exosomes) [28-30] and even bind their targets in different binding sites (5'UTR, coding region, and $3^{\prime}$ UTR) [31,32]. Several additional non-canonical binding clusters independent of seed region have been discovered [33]. It has also been reported that, under certain circumstances, instead of repression, miRNAs activate their target expression [34]. Finally, possible interactions have been observed between other ncRNAs and miRNA:mRNA complexes [35].

\section{Epigenetic Regulation of ICD-Hallmarks by miRNA}

Given their well-known contributions to cell death control [36] and autophagy [37], miRNAs may easily be envisioned to play key roles in the processes regulating ICD.

In the following section, we recapitulate the current data supporting epigenetic regulation of DAMPs by miRNAs. In particular, we have only focused on studies in which direct miRNA:mRNA interactions have been experimentally validated, e.g., by gene reporter or target protector-mediated assays [38]. Given that both miRNAs and DAMPs roles are so much context-dependent, we propose a classification of miRNA function (as tumor suppressor or oncomiRNA) solely based on factual experimental evidence. Surprisingly, we notice that they mainly function as tumor suppressors. For miRNA nomenclature, we decided to adapt and unify miRNA names and accession numbers according to the miRBase database, the primary repository for published miRNA, freely available at http:/ / www.mirbase.org/ (accessed on 25 January 2021). All data are summarized in Table 1 and schematized in Figure 2. 


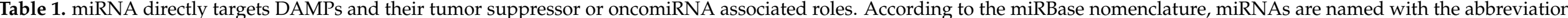

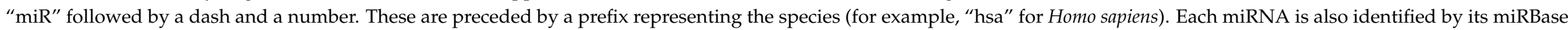

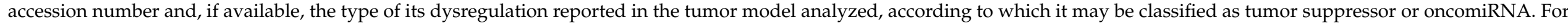
each targeted DAMP, the effects of its regulation are also described ( $\downarrow$ decrease/inhibition; $\uparrow$ increase/activation).

\begin{tabular}{|c|c|c|c|c|c|c|c|c|}
\hline miRNA & $\begin{array}{c}\text { miRBase Accession } \\
\text { Number }\end{array}$ & $\begin{array}{l}\text { Dysregulation in } \\
\text { Cancer vs. Normal } \\
\text { Counterparts }\end{array}$ & Target DAMP & $\begin{array}{l}\text { miRNA Binding } \\
\text { Site in Target Gene }\end{array}$ & Cancer Type & Effects & Role & Reference \\
\hline hsa-let-7e-5p & MIMAT0000066 & Not evaluated & HMGB1 & $3^{\prime} \mathrm{UTR}$ & Thyroid cancer & $\begin{array}{l}\downarrow \text { Migration } \\
\downarrow \text { Invasion }\end{array}$ & $\begin{array}{l}\text { Tumor } \\
\text { suppressor }\end{array}$ & $\begin{array}{c}\text { Ding et al., } 2019 \\
\text { [39] }\end{array}$ \\
\hline hsa-miR-107 & MIMAT0000104 & $\begin{array}{l}\text { Downregulation (tissues } \\
\text { and cell lines) }\end{array}$ & HMGB1 & $3^{\prime} \mathrm{UTR}$ & Breast cancer & $\begin{array}{c}\downarrow \text { Migration } \\
\downarrow \text { Proliferation } \\
\downarrow \text { Autophagy }\end{array}$ & $\begin{array}{l}\text { Tumor } \\
\text { suppressor }\end{array}$ & $\begin{array}{c}\text { Ai et al., } 2018 \\
\text { [40] }\end{array}$ \\
\hline hsa-miR-1179 & MIMAT0005824 & $\begin{array}{l}\text { Downregulation (tissues } \\
\text { and cell lines) }\end{array}$ & HMGB1 & $3^{\prime} \mathrm{UTR}$ & Gastric cancer & $\begin{array}{l}\downarrow \text { Proliferation } \\
\downarrow \downarrow \text { Invasion }\end{array}$ & $\begin{array}{l}\text { Tumor } \\
\text { suppressor }\end{array}$ & $\begin{array}{c}\text { Li et al., } 2019 \\
{[41]}\end{array}$ \\
\hline hsa-miR-1284 & MIMAT0005941 & $\begin{array}{l}\text { Downregulation (tissues } \\
\text { and cell lines) }\end{array}$ & HMGB1 & Not reported & Cervical cancer & $\begin{array}{c}\downarrow \text { Proliferation } \\
\downarrow \text { Invasion } \\
\uparrow \text { Cisplatin-induced apoptosis }\end{array}$ & $\begin{array}{l}\text { Tumor } \\
\text { suppressor }\end{array}$ & $\begin{array}{c}\text { Chen \& Li, } 2018 \\
\text { [42] }\end{array}$ \\
\hline \multirow{7}{*}{ hsa-miR-129-5p } & \multirow{7}{*}{ MIMAT0000242 } & Not evaluated & \multirow{7}{*}{ HMGB1 } & $3^{\prime} \mathrm{UTR}$ & Breast cancer & $\begin{array}{l}\downarrow \text { Irradiation-induced } \\
\text { autophagy } \\
\uparrow \text { Radiosensitivity }\end{array}$ & $\begin{array}{l}\text { Tumor } \\
\text { suppressor }\end{array}$ & $\begin{array}{l}\text { Luo et al., } 2015 \\
{[43]}\end{array}$ \\
\hline & & Not evaluated & & Not evaluated & Breast cancer & $\begin{array}{c}\downarrow \text { Autophagy } \\
\uparrow \text { Paclitaxel-induced apoptosis }\end{array}$ & $\begin{array}{l}\text { Tumor } \\
\text { suppressor }\end{array}$ & $\begin{array}{l}\text { Shi et al., } 2019 \\
\text { [44] }\end{array}$ \\
\hline & & Not evaluated & & Not reported & Colon cancer & $\downarrow$ Proliferation & $\begin{array}{l}\text { Tumor } \\
\text { suppressor }\end{array}$ & $\begin{array}{c}\text { Wu et al., } 2018 \\
{[45]}\end{array}$ \\
\hline & & $\begin{array}{c}\text { Downregulation (tissues } \\
\text { and cell lines) }\end{array}$ & & $3^{\prime} \mathrm{UTR}$ & Gastric cancer & $\begin{array}{c}\downarrow \text { Proliferation } \\
\uparrow \text { Apoptosis } \\
\end{array}$ & $\begin{array}{l}\text { Tumor } \\
\text { suppressor }\end{array}$ & $\begin{array}{c}\text { Feng et al., } 2020 \\
{[46]}\end{array}$ \\
\hline & & $\begin{array}{l}\text { Downregulation (cell } \\
\text { lines) }\end{array}$ & & $3^{\prime} \mathrm{UTR}$ & Gastric cancer & $\begin{array}{c}\downarrow \text { Proliferation } \\
\downarrow \text { Epithelial-mesenchymal } \\
\text { transition }\end{array}$ & $\begin{array}{l}\text { Tumor } \\
\text { suppressor }\end{array}$ & $\begin{array}{c}\text { Wang et al., } 2019 \\
\text { [47] }\end{array}$ \\
\hline & & Not evaluated & & $3^{\prime} \mathrm{UTR}$ & $\begin{array}{l}\text { Hepatocellular } \\
\text { carcinoma }\end{array}$ & $\begin{array}{l}\downarrow \text { Migration } \\
\downarrow \text { Invasion }\end{array}$ & $\begin{array}{l}\text { Tumor } \\
\text { suppressor }\end{array}$ & $\begin{array}{c}\text { Zhang et al., } 2017 \\
\text { [48] }\end{array}$ \\
\hline & & Downregulation (tissues) & & $3^{\prime} \mathrm{UTR}$ & Osteosarcoma & $\begin{array}{l}\downarrow \text { Proliferation } \\
\uparrow \text { Apoptosis }\end{array}$ & $\begin{array}{l}\text { Tumor } \\
\text { suppressor }\end{array}$ & $\begin{array}{l}\text { Liu et al., } 2017 \\
\text { [49] }\end{array}$ \\
\hline
\end{tabular}


Table 1. Cont.

\begin{tabular}{|c|c|c|c|c|c|c|c|c|}
\hline miRNA & $\begin{array}{c}\text { miRBase Accession } \\
\text { Number }\end{array}$ & $\begin{array}{l}\text { Dysregulation in } \\
\text { Cancer vs. Normal } \\
\text { Counterparts }\end{array}$ & Target DAMP & $\begin{array}{l}\text { miRNA Binding } \\
\text { Site in Target Gene }\end{array}$ & Cancer Type & Effects & Role & Reference \\
\hline \multirow{5}{*}{ hsa-miR-142-3p } & \multirow{5}{*}{ MIMAT0000434 } & Downregulation (tissues) & \multirow{4}{*}{ HMGB1 } & $3^{\prime} \mathrm{UTR}$ & Glioma & $\begin{array}{l}\downarrow \text { Proliferation } \\
\downarrow \downarrow \text { Invasion }\end{array}$ & $\begin{array}{l}\text { Tumor } \\
\text { suppressor }\end{array}$ & $\begin{array}{c}\text { Zhang et al., } 2018 \\
\text { [50] }\end{array}$ \\
\hline & & Not evaluated & & $3^{\prime} \mathrm{UTR}$ & $\begin{array}{l}\text { Non-small-cell } \\
\text { lung cancer }\end{array}$ & $\begin{array}{c}\downarrow \text { Starvation-induced } \\
\text { autophagy } \\
\uparrow \text { Cisplatin and } \\
\text { doxorubicin-chemosensitivity }\end{array}$ & $\begin{array}{l}\text { Tumor } \\
\text { suppressor }\end{array}$ & $\begin{array}{l}\text { Chen et al., } 2017 \\
\text { [51] }\end{array}$ \\
\hline & & $\begin{array}{l}\text { Downregulation (tissues } \\
\text { and cell lines) }\end{array}$ & & $3^{\prime} \mathrm{UTR}$ & $\begin{array}{l}\text { Non-small-cell } \\
\text { lung cancer }\end{array}$ & $\begin{array}{l}\downarrow \text { Proliferation } \\
\uparrow \text { Apoptosis }\end{array}$ & $\begin{array}{l}\text { Tumor } \\
\text { suppressor }\end{array}$ & Xiao \& Lu, 2015 \\
\hline & & Downregulation (tissues) & & $3^{\prime} \mathrm{UTR}$ & Osteosarcoma & $\begin{array}{l}\downarrow \text { Proliferation } \\
\uparrow \text { Apoptosis }\end{array}$ & $\begin{array}{l}\text { Tumor } \\
\text { suppressor }\end{array}$ & $\begin{array}{c}\text { Liu et al., } 2017 \\
\text { [49] }\end{array}$ \\
\hline & & Not evaluated & Hsp70 & $3^{\prime} \mathrm{UTR}$ & $\begin{array}{l}\text { Pancreatic ductal } \\
\text { adenocarcinoma }\end{array}$ & $\downarrow$ Proliferation & $\begin{array}{l}\text { Tumor } \\
\text { suppressor }\end{array}$ & $\begin{array}{c}\text { MacKenzie et al., } \\
2013 \\
{[53]}\end{array}$ \\
\hline hsa-miR-181b-5p & MIMAT0000257 & Not evaluated & HMGB1 & $3^{\prime} \mathrm{UTR}$ & $\begin{array}{c}\text { Acute myeloid } \\
\text { leukemia }\end{array}$ & $\begin{array}{c}\uparrow \text { Doxorubicin or } \\
\text { cytarabine-induced apoptosis }\end{array}$ & $\begin{array}{c}\text { Tumor } \\
\text { suppressor }\end{array}$ & $\begin{array}{c}\text { Lu et al., } 2014 \\
{[54]}\end{array}$ \\
\hline hsa-miR-193a-3p & MIMAT0000459 & Not evaluated & HMGB1 & $3^{\prime} \mathrm{UTR}$ & Lung cancer & $\begin{array}{l}\downarrow \text { Proliferation } \\
\downarrow \text { Migration }\end{array}$ & $\begin{array}{c}\text { Tumor } \\
\text { suppressor }\end{array}$ & $\begin{array}{l}\text { Wu et al., } 2018 \\
\text { [55] }\end{array}$ \\
\hline hsa-miR-200a-5p & MIMAT0001620 & Downregulation (tissues) & HMGB1 & $3^{\prime} \mathrm{UTR}$ & $\begin{array}{l}\text { Hepatocellular } \\
\text { carcinoma }\end{array}$ & Not determined & $\begin{array}{l}\text { Tumor } \\
\text { suppressor }\end{array}$ & $\begin{array}{c}\text { Li et al., } 2017 \\
{[56]}\end{array}$ \\
\hline \multirow[b]{2}{*}{ hsa-miR-200c-3p } & \multirow[b]{2}{*}{ MIMAT0000617 } & Not evaluated & \multirow[b]{2}{*}{ HMGB1 } & $3^{\prime} \mathrm{UTR}$ & Breast cancer & $\begin{array}{l}\downarrow \text { Invasion } \\
\downarrow \text { Migration }\end{array}$ & $\begin{array}{c}\text { Tumor } \\
\text { suppressor }\end{array}$ & $\begin{array}{c}\text { Chang et al., } 2014 \\
\text { [57] }\end{array}$ \\
\hline & & Not evaluated & & Not evaluated & Lung cancer & $\begin{array}{c}\downarrow \text { Invasion } \\
\downarrow \text { Migration } \\
\downarrow \text { Epithelial-mesenchymal } \\
\text { transition } \\
\end{array}$ & $\begin{array}{l}\text { Tumor } \\
\text { suppressor }\end{array}$ & $\begin{array}{l}\text { Liu et al., } 2017 \\
\text { [58] }\end{array}$ \\
\hline hsa-miR-205-5p & MIMAT0000266 & $\begin{array}{l}\text { Downregulation (tissues). } \\
\text { Moreover, it is } \\
\text { downregulated in } \\
\text { metastatic compared to } \\
\text { non-metastatic cancer }\end{array}$ & HMGB1 & $3^{\prime} \mathrm{UTR}$ & $\begin{array}{l}\text { Triple-negative } \\
\text { breast cancer }\end{array}$ & $\begin{array}{c}\downarrow \text { Invasion } \\
\downarrow \text { Migration } \\
\downarrow \text { Proliferation }\end{array}$ & $\begin{array}{l}\text { Tumor } \\
\text { suppressor }\end{array}$ & $\begin{array}{l}\text { Wang et al., } 2019 \\
\text { [59] }\end{array}$ \\
\hline
\end{tabular}


Table 1. Cont.

\begin{tabular}{|c|c|c|c|c|c|c|c|c|}
\hline miRNA & $\begin{array}{c}\text { miRBase Accession } \\
\text { Number }\end{array}$ & $\begin{array}{l}\text { Dysregulation in } \\
\text { Cancer vs. Normal } \\
\text { Counterparts }\end{array}$ & Target DAMP & $\begin{array}{l}\text { miRNA Binding } \\
\text { Site in Target Gene }\end{array}$ & Cancer Type & Effects & Role & Reference \\
\hline \multirow{3}{*}{ hsa-miR-218-5p } & \multirow{3}{*}{ MIMAT0000275 } & $\begin{array}{l}\text { Downregulation } \\
\text { Paclitaxel-resistant } \\
\text { compared to non-drug } \\
\text { resistant cells (cell lines) }\end{array}$ & \multirow{3}{*}{ HMGB1 } & $3^{\prime} \mathrm{UTR}$ & $\begin{array}{l}\text { Endometrial } \\
\text { carcinoma }\end{array}$ & $\begin{array}{c}\downarrow \text { Autophagy } \\
\uparrow \text { Paclitaxel-chemosensitivity }\end{array}$ & $\begin{array}{l}\text { Tumor } \\
\text { suppressor }\end{array}$ & $\begin{array}{c}\text { Ran et al., } 2015 \\
\text { [60] }\end{array}$ \\
\hline & & Not evaluated & & $3^{\prime} \mathrm{UTR}$ & Lung cancer & $\begin{array}{l}\downarrow \text { Invasion } \\
\downarrow \text { Migration }\end{array}$ & $\begin{array}{c}\text { Tumor } \\
\text { suppressor }\end{array}$ & $\begin{array}{c}\text { Zhang et al., } 2013 \\
\text { [61] }\end{array}$ \\
\hline & & Non evaluated & & $3^{\prime} \mathrm{UTR}$ & Prostate cancer & $\begin{array}{c}\downarrow \text { Invasion } \\
\downarrow \text { Migration } \\
\downarrow \text { Proliferation } \\
\uparrow \text { Apoptosis }\end{array}$ & $\begin{array}{l}\text { Tumor } \\
\text { suppressor }\end{array}$ & $\begin{array}{c}\text { Zhang et al., } 2019 \\
\text { [62] }\end{array}$ \\
\hline hsa-miR-223-3p & MIMAT0000280 & Not evaluated & Hsp90 & $3^{\prime} \mathrm{UTR}$ & Osteosarcoma & $\begin{array}{c}\downarrow \text { Proliferation } \\
\uparrow \text { Apoptosis } \\
\uparrow \text { Cell cycle G0/G1 arrest }\end{array}$ & $\begin{array}{l}\text { Tumor } \\
\text { suppressor }\end{array}$ & $\begin{array}{c}\text { Li et al., } 2012 \\
{[63]}\end{array}$ \\
\hline hsa-miR-223-5p & MIMAT0004570 & $\begin{array}{c}\text { Downregulation (tissues } \\
\text { and cell lines) }\end{array}$ & Hsp70 & $3^{\prime} \mathrm{UTR}$ & Osteosarcoma & $\uparrow$ Cisplastin-induced apoptosis & $\begin{array}{c}\text { Tumor } \\
\text { suppressor }\end{array}$ & $\begin{array}{c}\text { Tang et al., } 2018 \\
{[64]}\end{array}$ \\
\hline hsa-miR-320a-3p & MIMAT0000510 & Downregulation (tissues) & HMGB1 & $3^{\prime} \mathrm{UTR}$ & $\begin{array}{l}\text { Hepatocellular } \\
\text { carcinoma }\end{array}$ & $\begin{array}{l}\downarrow \text { Invasion } \\
\downarrow \text { Migration }\end{array}$ & $\begin{array}{c}\text { Tumor } \\
\text { suppressor }\end{array}$ & $\begin{array}{c}\text { Lv et al., } 2017 \\
{[65]}\end{array}$ \\
\hline hsa-miR-27a-3p & MIMAT0000084 & Upregulation (tissues) & Calreticulin & $3^{\prime} \mathrm{UTR}$ & $\begin{array}{l}\text { Colorectal } \\
\text { cancer }\end{array}$ & $\begin{array}{c}\downarrow \text { Mitoxantrone and } \\
\text { oxaliplain-induced apoptosis } \\
\downarrow \text { Autophagy } \\
\downarrow \text { MCH-I expression } \\
\downarrow \text { Dendritic cell maturation } \\
\downarrow \text { In situ immune cells } \\
\text { infiltration } \\
\uparrow \text { Tumor growth } \\
\uparrow \text { Liver metastasis }\end{array}$ & Onco-miRNA & $\begin{array}{c}\text { Colangelo et al., } \\
\text { 2016a and b } \\
{[67,68]}\end{array}$ \\
\hline hsa-miR-27b-3p & MIMAT0000419 & Not evaluated & Hsp90 & $3^{\prime} \mathrm{UTR}$ & $\begin{array}{l}\text { Non-small-cell } \\
\text { lung carcinoma }\end{array}$ & $\begin{array}{l}\downarrow \text { Migration } \\
\downarrow \text { Invasion }\end{array}$ & $\begin{array}{c}\text { Tumor } \\
\text { suppressor }\end{array}$ & $\begin{array}{c}\text { Dong et al., } 2019 \\
\text { [69] }\end{array}$ \\
\hline hsa-miR-34a-3p & MIMAT0004557 & Not evaluated & HMGB1 & $3^{\prime} \mathrm{UTR}$ & Retinoblastoma & $\begin{array}{c}\uparrow \text { Etoposide and } \\
\text { carboplatin-induced apoptosis } \\
\downarrow \text { Starvation-induced } \\
\text { autophagy }\end{array}$ & $\begin{array}{l}\text { Tumor } \\
\text { suppressor }\end{array}$ & $\begin{array}{l}\text { Liu et al., } 2014 \\
{[70]}\end{array}$ \\
\hline
\end{tabular}


Table 1. Cont.

\begin{tabular}{|c|c|c|c|c|c|c|c|c|}
\hline miRNA & $\begin{array}{c}\text { miRBase Accession } \\
\text { Number }\end{array}$ & $\begin{array}{l}\text { Dysregulation in } \\
\text { Cancer vs. Normal } \\
\text { Counterparts }\end{array}$ & Target DAMP & $\begin{array}{l}\text { miRNA Binding } \\
\text { Site in Target Gene }\end{array}$ & Cancer Type & Effects & Role & Reference \\
\hline \multirow{3}{*}{ hsa-miR-34a-5p } & \multirow{3}{*}{ MIMAT0000255 } & $\begin{array}{l}\text { Downregulation } \\
\text { (cell lines) }\end{array}$ & \multirow{3}{*}{ HMGB1 } & $3^{\prime} \mathrm{UTR}$ & $\begin{array}{l}\text { Acute Myeloid } \\
\text { Leukemia }\end{array}$ & $\begin{array}{l}\uparrow \text { Apoptosis } \\
\downarrow \text { Autophagy }\end{array}$ & $\begin{array}{l}\text { Tumor } \\
\text { suppressor }\end{array}$ & $\begin{array}{l}\text { Liu et al., } 2017 \\
{[58]}\end{array}$ \\
\hline & & Downregulation (tissues) & & $3^{\prime} \mathrm{UTR}$ & $\begin{array}{l}\text { Cervical (CaCx) } \\
\text { and colorectal } \\
(\mathrm{CRC}) \text { cancers }\end{array}$ & $\begin{array}{c}\downarrow \text { Invasion } \\
\downarrow \text { Migration } \\
\downarrow \text { Proliferation }\end{array}$ & $\begin{array}{l}\text { Tumor } \\
\text { suppressor }\end{array}$ & $\begin{array}{c}\text { Chandrasekaran } \\
\text { et al., 2016 } \\
\text { [71] }\end{array}$ \\
\hline & & $\begin{array}{l}\text { Downregulation (tissues } \\
\text { and cell lines) }\end{array}$ & & $3^{\prime} \mathrm{UTR}$ & $\begin{array}{l}\text { Cutaneous } \\
\text { squamous cell } \\
\text { carcinoma }\end{array}$ & $\begin{array}{c}\downarrow \text { Invasion } \\
\downarrow \text { Migration } \\
\downarrow \text { Proliferation }\end{array}$ & $\begin{array}{l}\text { Tumor } \\
\text { suppressor }\end{array}$ & $\begin{array}{l}\text { Li et al., } 2017 \\
\text { [72] }\end{array}$ \\
\hline hsa-miR-361-5p & MIMAT0000703 & $\begin{array}{c}\text { Downregulation (tissues } \\
\text { and cell lines) }\end{array}$ & Hsp90 & $3^{\prime} \mathrm{UTR}$ & Cervical cancer & $\begin{array}{c}\downarrow \text { Epithelial-mesenchymal } \\
\text { transition } \\
\downarrow \text { Invasion }\end{array}$ & $\begin{array}{l}\text { Tumor } \\
\text { suppressor }\end{array}$ & $\begin{array}{l}\text { Xu et al., } 2020 \\
\text { [73] }\end{array}$ \\
\hline hsa-miR-449a & MIMAT0001541 & $\begin{array}{l}\text { Downregulation (tissues } \\
\text { and cell lines) }\end{array}$ & HMGB1 & $3^{\prime} \mathrm{UTR}$ & $\begin{array}{l}\text { Non-small cell } \\
\text { lung cancer }\end{array}$ & $\begin{array}{c}\downarrow \text { Invasion } \\
\downarrow \text { Migration } \\
\downarrow \text { Proliferation }\end{array}$ & $\begin{array}{l}\text { Tumor } \\
\text { suppressor }\end{array}$ & $\begin{array}{l}\text { Wu et al., } 2019 \\
{[74]}\end{array}$ \\
\hline \multirow{3}{*}{ hsa-miR-505-3p } & \multirow{3}{*}{ MIMAT0002876 } & $\begin{array}{l}\text { Downregulation } \\
\quad \text { (cell lines) }\end{array}$ & \multirow{3}{*}{ HMGB1 } & $3^{\prime} \mathrm{UTR}$ & Gastric cancer & $\begin{aligned} & \downarrow \text { Migration } \\
& \downarrow \text { Proliferation } \\
& \uparrow \text { Apoptosis }\end{aligned}$ & $\begin{array}{l}\text { Tumor } \\
\text { suppressor }\end{array}$ & $\begin{array}{c}\text { Tian et al., } 2018 \\
\text { [75] }\end{array}$ \\
\hline & & Not evaluated & & Non evaluated & $\begin{array}{l}\text { Hepatocellular } \\
\text { carcinoma }\end{array}$ & $\begin{array}{c}\uparrow \text { Doxorubicin-induced } \\
\text { apoptosis }\end{array}$ & $\begin{array}{l}\text { Tumor } \\
\text { suppressor }\end{array}$ & $\begin{array}{c}\text { Lu et al., } 2018 \\
{[77]}\end{array}$ \\
\hline & & Downregulation (tissues) & & $3^{\prime} \mathrm{UTR}$ & Osteosarcoma & $\begin{array}{c}\downarrow \text { Invasion } \\
\downarrow \text { Migration } \\
\downarrow \text { Proliferation }\end{array}$ & $\begin{array}{l}\text { Tumor } \\
\text { suppressor }\end{array}$ & $\begin{array}{l}\text { Liu et al., } 2017 \\
{[78]}\end{array}$ \\
\hline hsa-miR-519d-3p & MIMAT0002853 & Downregulation (tissues) & HMGB1 & $3^{\prime} \mathrm{UTR}$ & Lung cancer & $\begin{array}{c}\downarrow \text { Invasion } \\
\downarrow \text { Migration } \\
\downarrow \text { Proliferation }\end{array}$ & $\begin{array}{l}\text { Tumor } \\
\text { suppressor }\end{array}$ & $\begin{array}{l}\text { Ye et al., } 2020 \\
\text { [79] }\end{array}$ \\
\hline hsa-miR-548b-3p & MIMAT0003254 & $\begin{array}{l}\text { Downregulation (tissues } \\
\text { and cell lines) }\end{array}$ & HMGB1 & $3^{\prime} \mathrm{UTR}$ & $\begin{array}{l}\text { Hepatocellular } \\
\text { carcinoma }\end{array}$ & $\begin{array}{c}\downarrow \text { Invasion } \\
\downarrow \text { Migration } \\
\downarrow \text { Proliferation } \\
\uparrow \text { Apoptosis }\end{array}$ & $\begin{array}{l}\text { Tumor } \\
\text { suppressor }\end{array}$ & $\begin{array}{c}\text { Yun et al., } 2019 \\
\text { [80] }\end{array}$ \\
\hline
\end{tabular}


Table 1. Cont.

\begin{tabular}{|c|c|c|c|c|c|c|c|c|}
\hline miRNA & $\begin{array}{c}\text { miRBase Accession } \\
\text { Number }\end{array}$ & $\begin{array}{l}\text { Dysregulation in } \\
\text { Cancer vs. Normal } \\
\text { Counterparts }\end{array}$ & Target DAMP & $\begin{array}{l}\text { miRNA Binding } \\
\text { Site in Target Gene }\end{array}$ & Cancer Type & Effects & Role & Reference \\
\hline hsa-miR-628-3p & MIMAT0003297 & Not evaluated & Hsp90 & $3^{\prime} \mathrm{UTR}$ & $\begin{array}{l}\text { Non-small-cell } \\
\text { lung carcinoma }\end{array}$ & $\begin{array}{l}\downarrow \text { Migration } \\
\uparrow \text { Apoptosis }\end{array}$ & $\begin{array}{c}\text { Tumor } \\
\text { suppressor }\end{array}$ & $\begin{array}{c}\text { Pan et al., } 2018 \\
\text { [81] }\end{array}$ \\
\hline hsa-miR-665 & MIMAT0004952 & $\begin{array}{l}\text { Downregulation (tissues } \\
\text { and cell lines) }\end{array}$ & HMGB1 & $3^{\prime} \mathrm{UTR}$ & Retinoblastoma & $\begin{array}{c}\downarrow \text { Invasion } \\
\downarrow \text { Migration } \\
\downarrow \text { Proliferation } \\
\uparrow \text { Apoptosis }\end{array}$ & $\begin{array}{c}\text { Tumor } \\
\text { suppressor }\end{array}$ & $\begin{array}{c}\text { Wang et al., } 2019 \\
\text { [82] }\end{array}$ \\
\hline
\end{tabular}




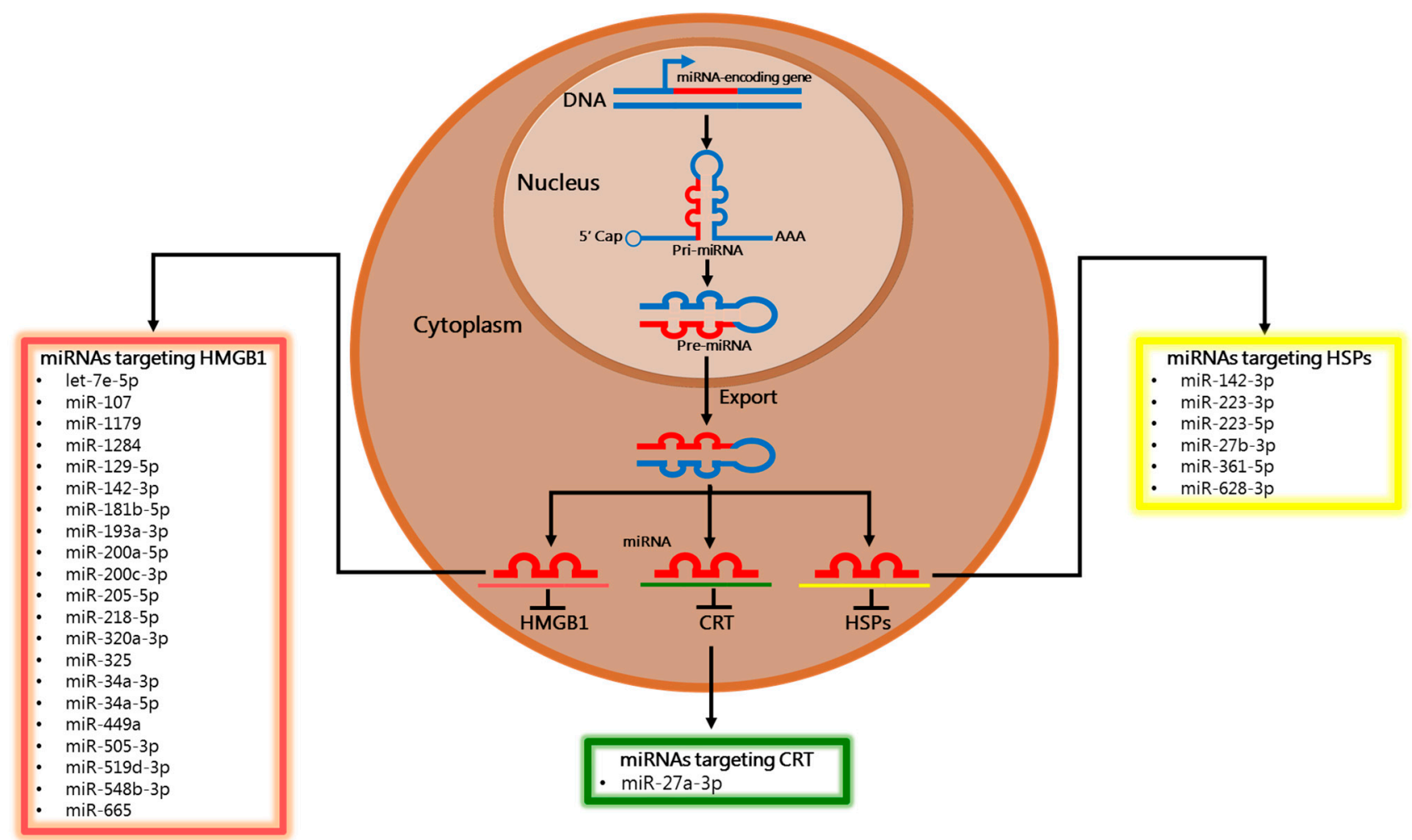

Figure 2. Immunogenic Cell Death-hallmarks targeted by miRNAs. The miRNA processing pathway initiates with the transcription of the primary miRNA (pri-miRNA) and its cleavage to generate the pre-miRNA. Then, pre-miRNA is exported from the nucleus to the cytoplasm, where it is cleaved to its mature miRNA. The functional strand of the mature miRNA has the major role to silence target mRNAs through different mechanisms. In this review, we summarize miRNAs that target well-known Immunogenic Cell Death-associated DAMPs, such as calreticulin (CRT), HMGB1, and Hsps (Hsp70, Hsp90).

\subsection{Calreticulin}

Calreticulin (CRT) is a chaperone protein mainly located in the lumen of the endoplasmic reticulum (ER). Given its high capacity of buffering calcium, it modulates calcium signaling and homeostasis [83]. Through these functions, CRT has important biological regulatory roles inside and outside the ER, and is involved in cancer, wound healing, cardiogenesis, autoimmune diseases, and neurological diseases [84].

In addition, CRT can be translocated to the surface of stressed and dying cells [12]. Exposure of CRT on the cell surface is a major factor in ICD, as it serves as an "eat me" engulfment signal for DCs, thus promoting the presentation of tumor-associated antigens to T cells [12]. In the context of cancer, CRT was identified as a direct target of miR-27a-3p. The role of this miRNA seems controversial, as it has been previously assigned with both anti-tumor [85-87] and pro-tumor properties [88,89]. miR-27a-3p downregulates CRT expression by inhibiting target mRNA translation [67]. It was also demonstrated that the miR-27a-3p throught targeting CRT modulates MHC class I surface exposure, and that, in particular, high miR-27a-3p concomitant with low CRT expression associates with enhanced tumor growth in vivo, colorectal cancer stage, development of metastasis, and impairment of $\mathrm{CD}^{+}$T-cell infiltration [67]. When colorectal cancer cells were subjected to ICD inducers (mitoxantrone and oxaliplatin), miR-27a-3p blocked CRT exposure, as well as ATP and HMGB1 secretion. Upon chemotherapeutic treatment, miR-27a-3p levels were inversely correlated with induction of apoptosis (by ICD inducers) and autophagy (by chloroquine). In parallel, soluble factors released by miR-27a-3p overexpressing tumor cells subjected to ICD failed to induce DC functional and phenotypic maturation [68]. The investigations of Colangelo et al. $[67,68]$ discussed in this section support the idea that 
the miR-27a-3p/CRT axis modulates the ICD program, especially by blocking the initial interaction between DCs and ICD-subjected tumor cells.

Collectively, data recapitulated here suggest that miR-27a can be postulated as an oncomiRNA in colorectal cancer, where its expression was shown to be upregulated, and that it may support tumor progression through downregulation of CRT-dependent immunostimulation.

\subsection{Heat Shock Proteins}

Heat-shock proteins (Hsps) are a group of molecular chaperones whose main cellular function is to ensure the precise (re)folding of proteins in stress conditions. They are usually located in the intracellular space wherein they exert prominent cytoprotective functions. Importantly, many tumors overexpress Hsps, presumably as an adaptive response to a "stressful" niche where they develop [90]. However, the ability of Hsps to contribute chaperoned peptides for antigen processing and MHC-restricted presentation has not yet been elucidated [91].

Under some circumstances, for example during ICD, at least two members of this family, Hsp70 and Hsp90, can be expressed at the cell surface, where they exhibit immunostimulatory properties $[92,93]$. Therefore, miRNAs that target Hsps expression are likely to have a significant impact on the tumor phenotype.

In pancreatic ductal adenocarcinoma, miR-142-3p inhibited cell proliferation by negatively regulating Hsp70 expression [53]. In addition to its proliferative role in cancer, Hsp70 was associated with chemoresistance. In this context, it was reported that miR-223-5p suppressed the chemoresistance of osteosarcoma cells to cisplatin through JNK/Jun signaling by downregulating Hsp70 expression; however, expression of miR-223-5p was reduced in osteosarcoma biopsies compared with paired non-tumor tissues [64]. Interestingly, also in an in vitro osteosarcoma model, ectopic expression of miR-223-3p, through Hsp90 downregulation, inhibited cell proliferation by inducing cell cycle arrest and apoptosis [63]. miR-27b-3p and miR-628-3p directly targeted Hsp90, resulting in suppression of non-smallcell lung carcinoma migration and invasion, and promoted apoptosis [69,81]. In addition, the lncRNA KCNQ1OT1 modulated Hsp90 expression by blocking miR-27b-3p [69]. The expression of miR-361-5p in cervical cancer was also downregulated by a lncRNA NEAT1, whereas its negative modulation of Hsp90 inhibited invasion and epithelial-mesenchymal transition (EMT) [73].

miRNAs described here act on the overall expression of Hsps, but the effects on postransductional modification and surface translocation are not revealed. However, the potential contribution of these miRNAs in modulating Hsps expression in the context of ICD remains an unmet question; thus, it is not yet elucidated whether they can play in favor of or against immunogenicity.

\subsection{HMGB1}

HMGB1 is a non-histone chromatin-binding protein that regulates different cellular functions according to its cellular localization. Within the nucleus, HMGB1 is involved in many DNA events (repair, transcription, stability, telomerase maintenance). In the cytoplasm, membrane, or extracellular space, several studies have demonstrated its ability to regulate cell proliferation, apoptosis, autophagy, inflammation, invasion, metastasis, and immunity, among others [94]. Paradoxically, HMGB1 has been attributed with both proand anti-tumoral properties. Relative to its immune functions, HMGB1 has been described as both a suppressor and an activator, which depends on receptors, targeted cells, and redox state [95].

A series of studies have demonstrated that miRNAs participate in the regulation of HMGB1 expression. By targeting HMGB1, miR-548b-3p [80] and miR-320-3p [65] suppressed hepatocellular carcinoma (HCC) cell proliferation, metastasis, and invasion while inducing apoptosis. In addition, HMGB1 expression was downregulated in HCC specimens and cell lines, which correlated with poor prognosis. Along this line, down- 
regulation of miR-325 [66] and miR-449a [74] correlated with poor prognosis in lung cancer patients, as these miRNAs negatively targeted HMGB1, resulting in decreased cell migration, invasion, and/or proliferation. It was also discovered that miR-107 [40] and miR-1179 [41], whose expression was downregulated in breast cancer and gastric cancer, respectively, inhibited autophagy, proliferation, and/or migration of tumor cells by directly suppressing HMGB1. While miR-1284 downregulation in cervical cancer tissues and cell lines correlated with poor survival, the miR-1284/HMGB1 axis suppressed proliferation and invasion [42]. Restoration of miR-665, by directly targeting HMGB1, suppressed cell proliferation, colony formation, migration, and invasion, and induced cell apoptosis in retinoblastoma [82]. Similar effects of let-7e-5p were observed in thyroid cancer, whereas similar effects were observed in thyroid cancer but through let-7e-5p [39].

Both mature sequences of mir-34a were shown to target HMGB1 directly. Antitumor events were promoted by the miR-34a-5p/HMGB1 axis in acute myeloid leukemia [96], cutaneous squamous cell carcinoma [72], cervical cancer, and colorectal cancers [71], and similar effects were exerted by miR-34a-3p/HMGB1 in retinoblastoma [70]. In acute myeloid leukemia, miR-181b-5p was significantly decreased, especially in relapsed/refractory patients. Upregulation of miR-181b-5p increased the chemosensitivity of leukemia cells and promoted drug-induced apoptosis via negative modulation of HMGB1 expression [54]. When a miR-200c-3p mimic was transfected into lung [58] and breast cancer cells [57], there was a significant decrease in cell migration, invasion, and epithelial to mesenchymal transition (EMT). These changes were associated in part with the downregulation of HMGB1 by miR-200c-3p. In triple negative breast cancer, the downregulation of miR-205-5p was negatively associated with progression and metastasis, and cell growth and EMT were inhibited by the miR-205-5p/HMGB1 axis [59].

The antitumor role of the miR-129-5p/HMGB1 axis was studied in osteosarcoma [45], hepatocellular carcinoma [48], breast cancer [43,44], gastric cancer [46,47], and colon cancer [45]. Downregulation of this miRNA expression was also reported in cancer cells lines and primary cancers, compared to their normal counterparts [46]. In these reports, ectopic expression of miR-129-5p was found to suppress migration, invasion, proliferation, and EMT, while it enhanced apoptosis, radio-, and chemosensitivity through HMGB1 downregulation. In addition, the miR-505-3p/HMGB1 axis exerted a negative impact on tumor progression in osteosarcoma [78], hepatocellular carcinoma [76,77], and gastric cancer [75]. Interestingly, it was found that the miRNA/HMGB1 axis was modulated by long noncoding RNAs (lncRNAs) and circular RNAs (circRNAs), most of them upregulated in cancer tissues. The lncRNA prostate cancer-associated transcript 1 (PCAT-1) [48] and MALAT1 $[45,49]$ inhibited reversed miRNA-dependent HMGB1 downregulation. Likewise, the lncRNA UCA1 exerted pro-tumoral activity in lung cancer, acting mechanistically by upregulating HMGB1 expression through miR-193a-3p inhibition [55]. The lncRNA PCA3 [62] downregulated the expression of miR-218-5p, whose negative targeting of HMGB1 was evaluated in endometrial carcinoma [60], lung cancer [61], and prostate cancer [62], leading to a decrease in tumor proliferation, migration, invasion, and chemoresistance. miR-142-3p has also been identified as a microRNA that suppressed HMGB1 expression in non-small-cell lung carcinoma [51,52] and glioma [50], therefore playing a major role in reducing tumor cell proliferation, invasion, apoptosis, and drug resistance (to cisplatin). Along this line, the lncRNA TP73-AS1 upregulated HMGB1 expression through sponging miR-142-3p [50] and also miR-200a-5p [56]. Finally, the circRNA circ_0007385 enhanced cell proliferation, migration, invasion, and chemoresistance in lung cancer through upregulating miR-519d-3p and thus downregulating HMGB1 [79].

Overall, the data recapitulated in the last two sections suggest that, at least in the described phenotypes, the cytoprotective roles of HMGB1, Hsp70, and Hsp90 were more relevant than their immunostimulatory properties. Indeed, their targeting miRNAs appeared to repress pro-tumoral phenotypes by directly inhibiting their expression, thereby functioning as potential tumor suppressors. Moreover, some of these miRNAs were shown to be downregulated in tumors compared to their normal counterparts (Table 1). These 
findings might enhance our knowledge of the molecular mechanisms underlying malignant progression, making miRNAs promising targets for therapeutic intervention.

\section{Modulation of Therapeutic Outcome through Targeting DAMPs by miRNA}

Nowadays, drug resistance represents a main obstacle in the clinical setting, leading to relapse and metastasis in several cancer types. Therefore, new and more innovative approaches are required to treat these malignancies efficiently. The new knowledge on miRNA molecular actions and their involvement in cancer-associated mechanisms has opened new perspectives in the development of more effective therapeutic strategies. As miRNAs modulate multiple signaling pathways associated with therapy response, modification in miRNA expression can lead to significant changes in disease evolution and cancer outcome. Over the last few decades, numerous studies have been published on miRNA regulation of the cancer treatment response [97]. Compelling evidence has shown that the fundamental mechanisms of resistance to different anticancer drugs might be attributed to aberrantly expressed miRNAs in a wide range of malignancies [98]. Some miRNAs that have been described above as tumor suppressors have also been shown to modulate the sensitivity to chemotherapeutic agents.

By directly targeting HMGB1, several miRNAs may synergistically promote chemosensitivity, increasing drug pro-apoptotic activity often impaired by HMGB1-promoted autophagy. Of those, Lu et al. reported that tumor cells exhibit greatly enhanced apoptosisrelated sensitivity to doxorubicin or cytarabine after transfection with the miR-181b mimic [54], and, in line with this, Chen \& Li showed that miR-1284 enhanced cisplatininduced apoptosis [42]. Ectopic expression of miR-505-3p was shown to enhance doxorubicininduced cell death and caspase-3 dependent apoptosis, via inactivation of the Akt pathway [77]. The PI3K/Akt/mTOR pathway has been implicated in HMGB1-mediated autophagy, which was shown to play an important pro-survival role and contribute to chemoresistance [99]. Moreover, Chen et al. reported that miR-142-3p overexpression inhibited autophagy by activating the PI3K/Akt/mTOR pathway through HMGB1, and thus resulting in the increase of cisplatin and doxorubicin-chemosensitivity [51]. In addition, HMGB1-mediated autophagic resistance to paclitaxel was identified by Ran et al., whereas upregulation of miR-218-5p could restore chemosensitivity [60]. Consistently, miR-129-5p was found to increase apoptosis during paclitaxel treatment, and the improvement in sensitivity was associated with inhibition of autophagy [44]. Liu et al. demonstrated that miR-34a-3p-mediated inhibition of autophagy could sensitize cells to etoposide and carboplatin-induced apoptosis [70]. Similarly, Tang et al. precisely described a feedback loop formed by miR-223-5p, Hsp70, and the JNK/Jun signaling pathway associated with the modulation of cisplatin-resistance [64].

Interestingly, most of the miRNAs with tumor suppressor functions are found downregulated in various cancer types compared to normal tissues: miR-505-3p in hepatocellular carcinoma [76] and osteosarcoma [78], miR-1284 in cervical cancer [42], miR-129-5p in osteosarcoma [49], miR-142-3p in non-small-cell lung cancer [52] and in osteosarcoma [49], and miR-223-5p in osteosarcoma [64], among others. This aberrant expression is closely implicated in cancer treatment resistance. However, even when the aberrant expression of those miRNA induced a substantial upregulation of ICD-associated DAMPs, none of the above-mentioned reports have explored its association with the induction of ICD. Elucidation of those features would require more targeted assays, which would allow us to obtain a more comprehensive view about the epigenetic modulation occurring in cancer cells undergoing ICD.

\section{Therapeutic Combination of ICD and miRNAs: A New Opportunity}

Innovative therapeutic approaches including miRNA-based agents together with current standard treatment modalities could importantly benefit cancer patients. Targeting miRNAs by restoring their expression seems to be an attractive tool for emerging, more effective individualized therapies. However, there are still significant challenges to over- 
come to ensure the efficient delivery of miRNA to the tumor in vivo, for example, off-target effects, poor serum stability, and ineffective, poorly selective cellular entry. Hence, the development of novel drug delivery systems with the capacity to target-directed transport and protection of such cargos is mandatory [100].

In the face of these challenges, two different delivery systems have been designed in order to combine miRNA and ICD-inducer administration.

Phung et al. successfully fabricated nanoparticles (NPs) for target-specific co-delivery of low-dose doxorubicin and miR-200c to cancer cells [101]. These mixed NPs were composed of two co-polymers: poly(D,L-lactide-co-glycolide)-polyethyleneimine (PLGAPEI) and folic acid (FA)-conjugated PLGA-block-poly(ethylene glycol) (PLGA-PEG-FA). Doxorubicin was encapsulated by the hydrophobic core formed by PLGA, whereas the negative charges of miR-200c were electrostatically absorbed by the cationic backbone of PEI. PEI cytotoxicity was reduced by PEG, which also conferred stability and the way to introduce folic acid (FA) [102]. Despite conferring $\mathrm{pH}$ and temperature stability, permeability, non-immunogenicity, capacity to be tagged, among other advantages, FA is extremely important in this system because it may increase the proper and selective uptake by tumor cells in both in vitro and especially in vivo settings. This is because folate receptors are overexpressed in numerous cancer types compared to corresponding normal tissues [103]. This configuration was in fact successful because it protected miR-200c from degradation in serum. In addition, the complete NPs were well tolerated by hosts, probably due, at least in part, to the substantially low dose of doxorubicin used [101].

Surprisingly, although miR-200c has been shown to downregulate HMGB1 expression directly $[57,58]$, this new NP-based platform that combined miR-200c and doxorubicin promoted ICD via the translocation of CRT to the cell surface and the release of HMGB1 in vitro and in vivo. Accordingly, DAMPs' modulation was accomplished by DCs' phenotypic maturation. In addition, $\mathrm{T}$ cell antitumor activity was enhanced, partially due to downregulation of PD-L1 by miR-200c [101].

Recently, Wang et al. designed another type of nanocarrier to deliver both miR1284 and cisplatin [104]. They generated liposomes composed of distearoylphosphatidylcholine (DSPC) succinylphosphatidylethanolamine (DSPE-mPEG), distearoyl-N-(3-carboxypropionoylpoly (ethyleneglycol) succinyl) phosphatidylethanolamine (DSPE-PEG-COOH), and 1,2-dioleoyl-3-trimethylammoniumpropane (DOTAP) to be loaded with $10 \%$ of cisplatin and surface-conjugated with the CD59 antibody. The presence of anti-CD59 on the NP surface conferred tumor selective accumulation properties, as CD59 has been shown to be overexpressed in cancer and associated with immune escape events [105]. This cationic liposome was able to bind the negatively charged miR-1284 electrostatically.

The pharmacokinetic analysis of the formulation indicated that the nanocarrier-based system prolonged the blood circulation of the drugs. The anticancer effects were only assessed in vitro and demonstrated a full internalization of the complex by tumor cells. As expected and according to previous results [42], co-delivery of miR-1284 and cisplatin synergistically inhibited cell viability and promoted apoptosis by HMGB1 downregulation [104]. Given these promising results, future in vivo analysis should be done to evaluate the pre-clinical efficacy of this formulation. The impact of this combination should also be studied in the context of ICD, given that cisplatin was shown to be an ICD inducer [4].

Together, these results provide guidance for a promising combination strategy to improve the clinical use and the immunostimulatory efficiency of ICD-inducing drugs and develop an effective and safe cancer therapeutic option.

\section{Future Challenges}

Understanding the regulation of ICD hallmarks is pivotal for a better exploitation of the different effects characterizing ICD inducers. In this review, we summarized studies that have reported that numerous miRNAs contributed to DAMP modulation, acting as either oncogenic miRNAs or tumor suppressor miRNAs. However, it is important to note that there is not much evidence regarding miRNA modulation by ICD, although it was 
reported that different miRNAs could contribute to ICD inducers therapeutic activities. Outstanding questions exist: Does a miRNA signature associated with ICD actually exist? Do specific miRNAs play a role in ICD in cancer cells?

As mentioned above, ICD-associated pathways are not tumor-exclusive. For that reason, when evaluating the role of an immunity modulator, it is necessary to integrate fully the different cellular actors and the molecular crosstalk established between them. In this scenario, it was demonstrated that miRNAs could be involved in the paracrine dialogue governing inter-cellular signaling within the tumor microenvironment. In this sense, dysregulation of endogenous miRNAs can be induced in immune cells by cancer cell-released DAMPs or miRNAs derived from cancer cells that can directly affect immune cell functions. Unlu et al. demonstrated that miR-34c and miR-214 were specifically upregulated in human PBMCs following incubation with conditioned media or tumor cell lysate from stressed cells, as part of the inflammatory response. In particular, the presence of HMGB1 within the paracrine stimulus was strongly associated with miRNA modulation [106]. Frank et al. provided evidence that miR-375 transfer from tumor cells to macrophages is crucial to alter the tumor-associated macrophage phenotype and the subsequent development of a tumor-promoting microenvironment [107]. Moreover, tumor-secreted miR-21 and miR-29a also can function by another mechanism, by binding as ligands to the Toll-like receptor (TLR) 8 , in immune cells, triggering a TLR-mediated prometastatic inflammatory response that ultimately may lead to tumor growth and metastasis. Thus, by acting as paracrine agonists of TLRs, secreted miRNAs are key regulators of the tumor microenvironment and are implicated in tumor-immune system communication [108]. Intriguingly, recently, Lee $\mathrm{J}$ et al. generated in the laboratory two distinct modified single-stranded RNAs (ssRNAs) and showed their ability to induce immunogenic cell death in different types of cancer cell lines. In particular, those ssRNA promoted DAMP release and consequent impact on cytokine secretion by immature DCs [109]. We have recently discovered that the employment of immunogenic tumor cell lysates as a tumor antigen source in the development of DC-based vaccines influenced the miRNA profile in DCs. Therefore, we wonder: Could cancer cells undergoing ICD exploit specific miRNAs to communicate with the tumor immune microenvironment? Could cancer cell-derived miRNAs become messengers for DCs during ICD?

These questions compelled us to match several multifaceted interactions to understand the effects of environmental factors on miRNA expression more comprehensively. In this sense, a novel discipline termed "molecular pathological epidemiology" (MPE) has been proposed as a comprehensive approach to precision medicine. MPE protocols include a multilevel research platform to integrate molecular pathologies, immune response, and clinical outcomes in cancer. The application of in vivo pathology together with new multi-omics techniques might contribute to a more profound understanding of miRNA heterogeneous regulation, their role in tumor biology and therapeutic response, and the putative link with the endogenous/exogenous environment (diet, drugs, including ICDinducing agents, microbiota, and germline genetics), further supporting the design of targeted, personalized therapies [110,111].

\section{Conclusions}

The discovery of miRNAs has deepened our knowledge of human diseases, especially cancer and its supporting epigenetic mechanisms. In this article, we have reviewed the evidence regarding the effects of miRNAs on the expression of DAMP mRNAs in different cancer types. Initially, we expected to identify several oncomiRNAs targeting DAMPs whose ectopic inhibition could promote and/or restore the immunogenic potential of therapeutic agents. Surprisingly, our hypothesis was only valid for CRT targeting, whereas miRNA-based downregulation of other DAMPs was in fact associated with suppressed cancer properties. We propose several reasons to explain, at least in part, these unexpected data. First of all, most DAMPs which were shown to be regulated by miRNAs are classified as constitutive (cDAMPs); hence, they are present inside healthy cells, and are released 
following immunogenic stimulus, exerting their proinflammatory functions in the extracellular space. Their ICD-associated modulation is mainly post-translational, whereas miRNA regulation is exerted at a pre-translational level. However, it seems possible that downregulation by miRNAs in cancer cells could temporarily limit their release and so their immunogenic roles. Further studies should be done in order to clarify this hypothesis. In contrast to cDAMPs, inducible DAMPs (iDAMPs) are not present in healthy cells but are induced and/or altered upon cell death (e.g., type 1 IFN). As far as we know, the regulation of iDAMPs by miRNAs has not yet been determined.

Secondly, when studying miRNAs, it is important to consider the relative promiscuity of their targets. As stated above, a given miRNA may have thousands of targets with significant differences in function. Even in the presence of restoration-of-function assays, this would lead to paradoxical conclusions about the role of miRNAs, in that a single miRNA may theoretically impact in opposite ways within the cell by targeting effectors with opposite functions. Moreover, interpretation of this paradox is even more complex when considering that miRNAs probably show different functions depending on the environment in which they are expressed.

However, given miRNAs' role in regulating cellular processes as cell death and autophagy, but also different immune escape mechanisms modulating antigen processing/presentation and immune inhibitory molecules in different types of cancer cells, it remains reasonable to speculate their involvement in ICD. This is especially true if we consider that miRNAs are implicated in tumor-immune system communication, a key feature of ICD.

Author Contributions: Investigation, M.J.L., J.D.C., V.C.; writing—original draft preparation, M.J.L., A.N.; writing—review and editing, M.J.L., J.D.C., N.B.R.V., V.C.; review and editing, V.C., J.D.C., N.B.R.V.; supervision, M.J.L., J.D.C. All authors have read and agreed to the published version of the manuscript.

Funding: This research was funded by: Italian Ministry of Health (Young Researcher Grant GR2011-02350476 to J.D.C.), “Fondazione con il Sud” (Brains2South 2015 PDR-0224 to J.D.C.), Agencia Nacional de Promoción Científica y Tecnológica (PICT-2017-1755 to M.J.L.), and Regione Campania, POR FESR 2014/20 RarePlatNet Project (Az. 1.2, CUP B63D18000380007 to V.C.).

Acknowledgments: M.J.L. holds a Fondazione Umberto Veronesi fellowship, A.N. holds a triennial fellowship from Regional Operational Program FSE 2014-2020-Axis III-Specific Objective 14 "Increasing the skills of the workforce and facilitating mobility, work teaching/reintegration (RA 10.4)".

Conflicts of Interest: The authors declare no conflict of interest.

\section{References}

1. Van Kempen, T.S.; Wenink, M.H.; Leijten, E.F.A.; Radstake, T.R.D.J.; Boes, M. Perception of Self: Distinguishing Autoimmunity from Autoinflammation. Nat. Rev. Rheumatol. 2015, 11, 483-492. [CrossRef] [PubMed]

2. Galluzzi, L.; Buqué, A.; Kepp, O.; Zitvogel, L.; Kroemer, G. Immunogenic Cell Death in Cancer and Infectious Disease. Nat. Rev. Immunol. 2017, 17, 97-111. [CrossRef]

3. Casares, N.; Pequignot, M.O.; Tesniere, A.; Ghiringhelli, F.; Roux, S.; Chaput, N.; Schmitt, E.; Hamai, A.; Hervas-Stubbs, S.; Obeid, M.; et al. Caspase-Dependent Immunogenicity of Doxorubicin-Induced Tumor Cell Death. J. Exp. Med. 2005, 202, $1691-1701$. [CrossRef]

4. Lamberti, M.J.; Nigro, A.; Mentucci, F.M.; Rumie Vittar, N.B.; Casolaro, V.; Dal Col, J. Dendritic Cells and Immunogenic Cancer Cell Death: A Combination for Improving Antitumor Immunity. Pharmaceutics 2020, 12, 256. [CrossRef]

5. Tang, R.; Xu, J.; Zhang, B.; Liu, J.; Liang, C.; Hua, J.; Meng, Q.; Yu, X.; Shi, S. Ferroptosis, Necroptosis, and Pyroptosis in Anticancer Immunity. J. Hematol. Oncol. 2020, 13, 110. [CrossRef] [PubMed]

6. Legrand, A.J.; Konstantinou, M.; Goode, E.F.; Meier, P. The Diversification of Cell Death and Immunity: Memento Mori. Mol. Cell 2019, 76, 232-242. [CrossRef] [PubMed]

7. Krysko, D.V.; Garg, A.D.; Kaczmarek, A.; Krysko, O.; Agostinis, P.; Vandenabeele, P. Immunogenic Cell Death and DAMPs in Cancer Therapy. Nat. Rev. Cancer 2012, 12, 860-875. [CrossRef] [PubMed]

8. Cruickshank, B.; Giacomantonio, M.; Marcato, P.; McFarland, S.; Pol, J.; Gujar, S. Dying to Be Noticed: Epigenetic Regulation of Immunogenic Cell Death for Cancer Immunotherapy. Front. Immunol. 2018, 9, 654. [CrossRef] [PubMed] 
9. Bloy, N.; Garcia, P.; Laumont, C.M.; Pitt, J.M.; Sistigu, A.; Stoll, G.; Yamazaki, T.; Bonneil, E.; Buqué, A.; Humeau, J.; et al. Immunogenic Stress and Death of Cancer Cells: Contribution of Antigenicity vs Adjuvanticity to Immunosurveillance. Immunol. Rev. 2017, 280, 165-174. [CrossRef]

10. Portela, A.; Esteller, M. Epigenetic Modifications and Human Disease. Nat. Biotechnol. 2010, 28, 1057-1068. [CrossRef] [PubMed]

11. Fucikova, J.; Kepp, O.; Kasikova, L.; Petroni, G.; Yamazaki, T.; Liu, P.; Zhao, L.; Spisek, R.; Kroemer, G.; Galluzzi, L. Detection of Immunogenic Cell Death and Its Relevance for Cancer Therapy. Cell Death Dis. 2020, 11, 1013. [CrossRef] [PubMed]

12. Obeid, M.; Tesniere, A.; Ghiringhelli, F.; Fimia, G.M.; Apetoh, L.; Perfettini, J.-L.; Castedo, M.; Mignot, G.; Panaretakis, T.; Casares, N.; et al. Calreticulin Exposure Dictates the Immunogenicity of Cancer Cell Death. Nat. Med. 2007, 13, 54-61. [CrossRef]

13. Panaretakis, T.; Kepp, O.; Brockmeier, U.; Tesniere, A.; Bjorklund, A.-C.; Chapman, D.C.; Durchschlag, M.; Joza, N.; Pierron, G.; van Endert, P.; et al. Mechanisms of Pre-Apoptotic Calreticulin Exposure in Immunogenic Cell Death. EMBO J. 2009, 28, 578-590. [CrossRef]

14. Martins, I.; Wang, Y.; Michaud, M.; Ma, Y.; Sukkurwala, A.Q.; Shen, S.; Kepp, O.; Métivier, D.; Galluzzi, L.; Perfettini, J.-L.; et al. Molecular Mechanisms of ATP Secretion during Immunogenic Cell Death. Cell Death Differ. 2014, 21, 79-91. [CrossRef]

15. Aymeric, L.; Apetoh, L.; Ghiringhelli, F.; Tesniere, A.; Martins, I.; Kroemer, G.; Smyth, M.J.; Zitvogel, L. Tumor Cell Death and ATP Release Prime Dendritic Cells and Efficient Anticancer Immunity. Cancer Res. 2010, 70, 855-858. [CrossRef]

16. Ghiringhelli, F.; Apetoh, L.; Tesniere, A.; Aymeric, L.; Ma, Y.; Ortiz, C.; Vermaelen, K.; Panaretakis, T.; Mignot, G.; Ullrich, E.; et al. Activation of the NLRP3 Inflammasome in Dendritic Cells Induces IL-1beta-Dependent Adaptive Immunity against Tumors. Nat. Med. 2009, 15, 1170-1178. [CrossRef]

17. Sistigu, A.; Yamazaki, T.; Vacchelli, E.; Chaba, K.; Enot, D.P.; Adam, J.; Vitale, I.; Goubar, A.; Baracco, E.E.; Remédios, C.; et al. Cancer Cell-Autonomous Contribution of Type I Interferon Signaling to the Efficacy of Chemotherapy. Nat. Med. 2014, 20, 1301-1309. [CrossRef]

18. Lamberti, M.J.; Mentucci, F.M.; Roselli, E.; Araya, P.; Rivarola, V.A.; Rumie Vittar, N.B.; Maccioni, M. Photodynamic Modulation of Type 1 Interferon Pathway on Melanoma Cells Promotes Dendritic Cell Activation. Front. Immunol. 2019, 10, 2614. [CrossRef] [PubMed]

19. Spisek, R.; Charalambous, A.; Mazumder, A.; Vesole, D.H.; Jagannath, S.; Dhodapkar, M.V. Bortezomib Enhances Dendritic Cell (DC)-Mediated Induction of Immunity to Human Myeloma via Exposure of Cell Surface Heat Shock Protein 90 on Dying Tumor Cells: Therapeutic Implications. Blood 2007, 109, 4839-4845. [CrossRef]

20. Yamazaki, T.; Hannani, D.; Poirier-Colame, V.; Ladoire, S.; Locher, C.; Sistigu, A.; Prada, N.; Adjemian, S.; Catani, J.P.; Freudenberg, M.; et al. Defective Immunogenic Cell Death of HMGB1-Deficient Tumors: Compensatory Therapy with TLR4 Agonists. Cell Death Differ. 2014, 21, 69-78. [CrossRef]

21. Yatim, N.; Cullen, S.; Albert, M.L. Dying Cells Actively Regulate Adaptive Immune Responses. Nat. Rev. Immunol. 2017, 17, 262-275. [CrossRef] [PubMed]

22. Zelenay, S.; Reis e Sousa, C. Adaptive Immunity after Cell Death. Trends Immunol. 2013, 34, 329-335. [CrossRef] [PubMed]

23. Montico, B.; Nigro, A.; Casolaro, V.; Dal Col, J. Immunogenic Apoptosis as a Novel Tool for Anticancer Vaccine Development. Int. J. Mol. Sci. 2018, 19, 594. [CrossRef] [PubMed]

24. Denzler, R.; McGeary, S.E.; Title, A.C.; Agarwal, V.; Bartel, D.P.; Stoffel, M. Impact of MicroRNA Levels, Target-Site Complementarity, and Cooperativity on Competing Endogenous RNA-Regulated Gene Expression. Mol. Cell 2016, 64, 565-579. [CrossRef] [PubMed]

25. Ni, W.-J.; Leng, X.-M. Dynamic MiRNA-MRNA Paradigms: New Faces of MiRNAs. Biochem. Biophys. Rep. 2015, 4, 337-341. [CrossRef] [PubMed]

26. Hanahan, D.; Weinberg, R.A. Hallmarks of Cancer: The Next Generation. Cell 2011, 144, 646-674. [CrossRef] [PubMed]

27. Peng, Y.; Croce, C.M. The Role of MicroRNAs in Human Cancer. Signal Transduct. Target. Ther. 2016, 1, 15004. [CrossRef]

28. Barrey, E.; Saint-Auret, G.; Bonnamy, B.; Damas, D.; Boyer, O.; Gidrol, X. Pre-MicroRNA and Mature MicroRNA in Human Mitochondria. PLoS ONE 2011, 6, e20220. [CrossRef]

29. Valadi, H.; Ekström, K.; Bossios, A.; Sjöstrand, M.; Lee, J.J.; Lötvall, J.O. Exosome-Mediated Transfer of MRNAs and MicroRNAs Is a Novel Mechanism of Genetic Exchange between Cells. Nat. Cell Biol. 2007, 9, 654-659. [CrossRef]

30. Liang, H.; Zhang, J.; Zen, K.; Zhang, C.-Y.; Chen, X. Nuclear MicroRNAs and Their Unconventional Role in Regulating Non-Coding RNAs. Protein Cell 2013, 4, 325-330. [CrossRef]

31. Brümmer, A.; Hausser, J. MicroRNA Binding Sites in the Coding Region of MRNAs: Extending the Repertoire of PostTranscriptional Gene Regulation. Bioessays News Rev. Mol. Cell. Dev. Biol. 2014, 36, 617-626. [CrossRef]

32. Lytle, J.R.; Yario, T.A.; Steitz, J.A. Target MRNAs Are Repressed as Efficiently by MicroRNA-Binding Sites in the $5^{\prime}$ UTR as in the 3' UTR. Proc. Natl. Acad. Sci. USA 2007, 104, 9667-9672. [CrossRef] [PubMed]

33. Helwak, A.; Kudla, G.; Dudnakova, T.; Tollervey, D. Mapping the Human MiRNA Interactome by CLASH Reveals Frequent Noncanonical Binding. Cell 2013, 153, 654-665. [CrossRef]

34. Vasudevan, S.; Tong, Y.; Steitz, J.A. Switching from Repression to Activation: MicroRNAs Can up-Regulate Translation. Science 2007, 318, 1931-1934. [CrossRef] [PubMed]

35. Yoon, J.-H.; Abdelmohsen, K.; Gorospe, M. Functional Interactions among MicroRNAs and Long Noncoding RNAs. Semin. Cell Dev. Biol. 2014, 34, 9-14. [CrossRef] 
36. Shirjang, S.; Mansoori, B.; Asghari, S.; Duijf, P.H.G.; Mohammadi, A.; Gjerstorff, M.; Baradaran, B. MicroRNAs in Cancer Cell Death Pathways: Apoptosis and Necroptosis. Free Radic. Biol. Med. 2019, 139, 1-15. [CrossRef]

37. Shan, C.; Chen, X.; Cai, H.; Hao, X.; Li, J.; Zhang, Y.; Gao, J.; Zhou, Z.; Li, X.; Liu, C.; et al. The Emerging Roles of AutophagyRelated MicroRNAs in Cancer. Int. J. Biol. Sci. 2021, 17, 134-150. [CrossRef] [PubMed]

38. Thomson, D.W.; Bracken, C.P.; Goodall, G.J. Experimental Strategies for MicroRNA Target Identification. Nucleic Acids Res. 2011, 39, 6845-6853. [CrossRef]

39. Ding, C.; Yu, H.; Shi, C.; Shi, T.; Qin, H.; Cui, Y. MiR-Let-7e Inhibits Invasion and Magration and Regulates HMGB1 Expression in Papillary Thyroid Carcinoma. Biomed. Pharmacother. 2019, 110, 528-536. [CrossRef]

40. Ai, H.; Zhou, W.; Wang, Z.; Qiong, G.; Chen, Z.; Deng, S. MicroRNAs-107 Inhibited Autophagy, Proliferation, and Migration of Breast Cancer Cells by Targeting HMGB1. J. Cell. Biochem. 2019, 120, 8696-8705. [CrossRef]

41. Li, Y.; Qin, C. MiR-1179 Inhibits the Proliferation of Gastric Cancer Cells by Targeting HMGB1. Hum. Cell 2019, 32, 352-359. [CrossRef]

42. Chen, J.; Li, G. MiR-1284 Enhances Sensitivity of Cervical Cancer Cells to Cisplatin via Downregulating HMGB1. Biomed. Pharmacother. 2018, 107, 997-1003. [CrossRef]

43. Luo, J.; Chen, J.; He, L. Mir-129-5p Attenuates Irradiation-Induced Autophagy and Decreases Radioresistance of Breast Cancer Cells by Targeting HMGB1. Med. Sci. Monit. 2015, 21, 4122-4129. [CrossRef] [PubMed]

44. Shi, Y.; Gong, W.; Lu, L.; Wang, Y.; Ren, J. Upregulation of MiR-129-5p Increases the Sensitivity to Taxol through Inhibiting HMGB1-Mediated Cell Autophagy in Breast Cancer MCF-7 Cells. Braz. J. Med. Biol. Res. 2019, 52, e8657. [CrossRef]

45. Wu, Q.; Meng, W.-Y.; Jie, Y.; Zhao, H. LncRNA MALAT1 Induces Colon Cancer Development by Regulating MiR-129-5p/HMGB1 Axis. J. Cell. Physiol. 2018, 233, 6750-6757. [CrossRef] [PubMed]

46. Feng, J.; Guo, J. MiR-129-5p Inhibits Proliferation of Gastric Cancer Cells through Targeted Inhibition on HMGB1 Expression. Eur. Rev. Med. Pharmacol. Sci. 2020, 24, 3665-3673. [PubMed]

47. Wang, S.; Chen, Y.; Yu, X.; Lu, Y.; Wang, H.; Wu, F.; Teng, L. MiR-129-5p Attenuates Cell Proliferation and Epithelial Mesenchymal Transition via HMGB1 in Gastric Cancer. Pathol. Res. Pract. 2019, 215, 676-682. [CrossRef]

48. Zhang, D.; Cao, J.; Zhong, Q.; Zeng, L.; Cai, C.; Lei, L.; Zhang, W.; Liu, F. Long Noncoding RNA PCAT-1 Promotes Invasion and Metastasis via the MiR-129-5p-HMGB1 Signaling Pathway in Hepatocellular Carcinoma. Biomed. Pharmacother. 2017, 95, 1187-1193. [CrossRef] [PubMed]

49. Liu, K.; Huang, J.; Ni, J.; Song, D.; Ding, M.; Wang, J.; Huang, X.; Li, W. MALAT1 Promotes Osteosarcoma Development by Regulation of HMGB1 via MiR-142-3p and MiR-129-5p. Cell Cycle 2017, 16, 578-587. [CrossRef]

50. Zhang, R.; Jin, H.; Lou, F. The Long Non-Coding RNA TP73-AS1 Interacted With MiR-142 to Modulate Brain Glioma Growth Through HMGB1/RAGE Pathway. J. Cell. Biochem. 2018, 119, 3007-3016. [CrossRef]

51. Chen, Y.; Zhou, X.; Qiao, J.; Bao, A. MiR-142-3p Overexpression Increases Chemo-Sensitivity of NSCLC by Inhibiting HMGB1Mediated Autophagy. Cell. Physiol. Biochem. 2017, 41, 1370-1382. [CrossRef]

52. Xiao, P.; Liu, W.-L. MiR-142-3p Functions as a Potential Tumor Suppressor Directly Targeting HMGB1 in Non-Small-Cell Lung Carcinoma. Int. J. Clin. Exp. Pathol. 2015, 8, 10800-10807.

53. MacKenzie, T.N.; Mujumdar, N.; Banerjee, S.; Sangwan, V.; Sarver, A.; Vickers, S.; Subramanian, S.; Saluja, A.K. Triptolide Induces the Expression of MiR-142-3p: A Negative Regulator of Heat Shock Protein 70 and Pancreatic Cancer Cell Proliferation. Mol. Cancer Ther. 2013, 12, 1266-1275. [CrossRef] [PubMed]

54. Lu, F.; Zhang, J.; Ji, M.; Li, P.; Du, Y.; Wang, H.; Zang, S.; Ma, D.; Sun, X.; Ji, C. MiR-181b Increases Drug Sensitivity in Acute Myeloid Leukemia via Targeting HMGB1 and Mcl-1. Int. J. Oncol. 2014, 45, 383-392. [CrossRef] [PubMed]

55. Wu, H.; Zhou, C. Long Non-Coding RNA UCA1 Promotes Lung Cancer Cell Proliferation and Migration via MicroRNA193a/HMGB1 Axis. Biochem. Biophys. Res. Commun. 2018, 496, 738-745. [CrossRef] [PubMed]

56. Li, S.; Huang, Y.; Huang, Y.; Fu, Y.; Tang, D.; Kang, R.; Zhou, R.; Fan, X. The Long Non-Coding RNA TP73-AS1 Modulates HCC Cell Proliferation through MiR-200a-Dependent HMGB1/RAGE Regulation. J. Exp. Clin. Cancer Res. 2017, 36, 51. [CrossRef]

57. Chang, B.; Wang, D.; Xing, J.; Yang, S.; Chu, Q.; Yu, S. MiR-200c Inhibits Metastasis of Breast Cancer Cells by Targeting HMGB1. J. Huazhong Univ. Sci. Technol. Med. Sci. 2014, 34, 201-206. [CrossRef] [PubMed]

58. Liu, P.-L.; Liu, W.-L.; Chang, J.-M.; Chen, Y.-H.; Liu, Y.-P.; Kuo, H.-F.; Hsieh, C.-C.; Ding, Y.-S.; Chen, W.-W.; Chong, I.-W. MicroRNA-200c Inhibits Epithelial-Mesenchymal Transition, Invasion, and Migration of Lung Cancer by Targeting HMGB1. PLoS ONE 2017, 12, e0180844. [CrossRef]

59. Wang, L.; Kang, F.; Wang, J.; Yang, C.; He, D. Downregulation of MiR-205 Contributes to Epithelial-Mesenchymal Transition and Invasion in Triple-Negative Breast Cancer by Targeting HMGB1-RAGE Signaling Pathway. Anticancer Drugs 2019, 30, $225-232$. [CrossRef]

60. Ran, X.; Yang, J.; Liu, C.; Zhou, P.; Xiao, L.; Zhang, K. MiR-218 Inhibits HMGB1-Mediated Autophagy in Endometrial Carcinoma Cells during Chemotherapy. Int. J. Clin. Exp. Pathol. 2015, 8, 6617-6626. [PubMed]

61. Zhang, C.; Ge, S.; Hu, C.; Yang, N.; Zhang, J. MiRNA-218, a New Regulator of HMGB1, Suppresses Cell Migration and Invasion in Non-Small Cell Lung Cancer. Acta Biochim. Biophys. Sin. 2013, 45, 1055-1061. [CrossRef]

62. Zhang, G.; He, X.; Ren, C.; Lin, J.; Wang, Q. Long Noncoding RNA PCA3 Regulates Prostate Cancer through Sponging MiR-218-5p and Modulating High Mobility Group Box 1. J. Cell. Physiol. 2019, 234, 13097-13109. [CrossRef] [PubMed] 
63. Li, G.; Cai, M.; Fu, D.; Chen, K.; Sun, M.; Cai, Z.; Cheng, B. Heat Shock Protein 90B1 Plays an Oncogenic Role and Is a Target of MicroRNA-223 in Human Osteosarcoma. Cell. Physiol. Biochem. 2012, 30, 1481-1490. [CrossRef]

64. Tang, Q.; Yuan, Q.; Li, H.; Wang, W.; Xie, G.; Zhu, K.; Li, D. MiR-223/Hsp70/JNK/JUN/MiR-223 Feedback Loop Modulates the Chemoresistance of Osteosarcoma to Cisplatin. Biochem. Biophys. Res. Commun. 2018, 497, 827-834. [CrossRef]

65. Lv, G.; Wu, M.; Wang, M.; Jiang, X.; Du, J.; Zhang, K.; Li, D.; Ma, N.; Peng, Y.; Wang, L.; et al. MiR-320a Regulates High Mobility Group Box 1 Expression and Inhibits Invasion and Metastasis in Hepatocellular Carcinoma. Liver Int. 2017, 37, 1354-1364. [CrossRef] [PubMed]

66. Yao, S.; Zhao, T.; Jin, H. Expression of MicroRNA-325-3p and Its Potential Functions by Targeting HMGB1 in Non-Small Cell Lung Cancer. Biomed. Pharmacother. 2015, 70, 72-79. [CrossRef]

67. Colangelo, T.; Polcaro, G.; Ziccardi, P.; Pucci, B.; Muccillo, L.; Galgani, M.; Fucci, A.; Milone, M.R.; Budillon, A.; Santopaolo, M.; et al. Proteomic Screening Identifies Calreticulin as a MiR-27a Direct Target Repressing MHC Class I Cell Surface Exposure in Colorectal Cancer. Cell Death Dis. 2016, 7, e2120. [CrossRef]

68. Colangelo, T.; Polcaro, G.; Ziccardi, P.; Muccillo, L.; Galgani, M.; Pucci, B.; Rita Milone, M.; Budillon, A.; Santopaolo, M.; Mazzoccoli, G.; et al. The MiR-27a-Calreticulin Axis Affects Drug-Induced Immunogenic Cell Death in Human Colorectal Cancer Cells. Cell Death Dis. 2016, 7, e2108. [CrossRef]

69. Dong, Z.; Yang, P.; Qiu, X.; Liang, S.; Guan, B.; Yang, H.; Li, F.; Sun, L.; Liu, H.; Zou, G.; et al. KCNQ1OT1 Facilitates Progression of Non-small-cell Lung Carcinoma via Modulating MiRNA-27b-3p/HSP90AA1 Axis. J. Cell. Physiol. 2019, 234, 11304-11314. [CrossRef]

70. Liu, K.; Huang, J.; Xie, M.; Yu, Y.; Zhu, S.; Kang, R.; Cao, L.; Tang, D.; Duan, X. MIR34A Regulates Autophagy and Apoptosis by Targeting HMGB1 in the Retinoblastoma Cell. Autophagy 2014, 10, 442-452. [CrossRef]

71. Chandrasekaran, K.S.; Sathyanarayanan, A.; Karunagaran, D. Downregulation of HMGB1 by MiR-34a Is Sufficient to Suppress Proliferation, Migration and Invasion of Human Cervical and Colorectal Cancer Cells. Tumor Biol. 2016, 37, 13155-13166. [CrossRef]

72. Li, S.; Luo, C.; Zhou, J.; Zhang, Y. MicroRNA-34a Directly Targets High-mobility Group Box 1 and Inhibits the Cancer Cell Proliferation, Migration and Invasion in Cutaneous Squamous Cell Carcinoma. Exp. Ther. Med. 2017, 14, 5611-5618. [CrossRef] [PubMed]

73. Xu, D.; Dong, P.; Xiong, Y.; Yue, J.; Konno, Y.; Ihira, K.; Kobayashi, N.; Todo, Y.; Watari, H. MicroRNA-361-Mediated Inhibition of HSP90 Expression and EMT in Cervical Cancer Is Counteracted by Oncogenic LncRNA NEAT1. Cells 2020, 9, 632. [CrossRef] [PubMed]

74. Wu, D.; Liu, J.; Chen, J.; He, H.; Ma, H.; Lv, X. MiR-449a Suppresses Tumor Growth, Migration, and Invasion in Non-Small Cell Lung Cancer by Targeting a HMGB1-Mediated NF-KB Signaling Pathway. Oncol. Res. Featur. Preclin. Clin. Cancer Ther. 2019, 27, 227-235. [CrossRef]

75. Tian, L.; Wang, Z.; Hao, J.; Zhang, X. MiR-505 Acts as a Tumor Suppressor in Gastric Cancer Progression through Targeting HMGB1. J. Cell. Biochem. 2019, 120, 8044-8052. [CrossRef] [PubMed]

76. Lu, L.; Qiu, C.; Li, D.; Bai, G.; Liang, J.; Yang, Q. MicroRNA-505 Suppresses Proliferation and Invasion in Hepatoma Cells by Directly Targeting High-Mobility Group Box 1. Life Sci. 2016, 157, 12-18. [CrossRef] [PubMed]

77. Lu, L.; Zhang, D.; Xu, Y.; Bai, G.; Lv, Y.; Liang, J. MiR-505 Enhances Doxorubicin-Induced Cytotoxicity in Hepatocellular Carcinoma through Repressing the Akt Pathway by Directly Targeting HMGB1. Biomed. Pharmacother. 2018, 104, 613-621. [CrossRef]

78. Liu, Y.-J.; Li, W.; Chang, F.; Liu, J.-N.; Lin, J.-X.; Chen, D.-X. MicroRNA-505 Is Downregulated in Human Osteosarcoma and Regulates Cell Proliferation, Migration and Invasion. Oncol. Rep. 2017, 39, 491-500. [CrossRef]

79. Ye, Y.; Zhao, L.; Li, Q.; Xi, C.; Li, Y.; Li, Z. Circ_0007385 Served as Competing Endogenous for MiR-519d-3p to Suppress Malignant Behaviors and Cisplatin Resistance of Non-small Cell Lung Cancer Cells. Thorac. Cancer 2020, 11, 2196-2208. [CrossRef]

80. Yun, Z.; Meng, F.; Jiang, P.; Yue, M.; Li, S. MicroRNA-548b Suppresses Aggressive Phenotypes of Hepatocellular Carcinoma by Directly Targeting High-Mobility Group Box 1 MRNA. Cancer Manag. Res. 2019, 11, 5821-5834. [CrossRef]

81. Pan, J.; Jiang, F.; Zhou, J.; Wu, D.; Sheng, Z.; Li, M. HSP90: A Novel Target Gene of MiRNA-628-3p in A549 Cells. BioMed Res. Int. 2018, 2018, 1-10. [CrossRef]

82. Wang, S.; Du, S.; Lv, Y.; Zhang, F.; Wang, W. MicroRNA-665 Inhibits the Oncogenicity of Retinoblastoma by Directly Targeting High-Mobility Group Box 1 and Inactivating the Wnt/ $\beta$-Catenin Pathway. Cancer Manag. Res. 2019, 11, 3111-3123. [CrossRef]

83. Kwon, M.S.; Park, C.S.; Choi, K.; Ahnn, J.; Kim, J.I.; Eom, S.H.; Kaufman, S.J.; Song, W.K. Calreticulin Couples Calcium Release and Calcium Influx in Integrin-Mediated Calcium Signaling. Mol. Biol. Cell 2000, 11, 1433-1443. [CrossRef]

84. Wang, W.-A.; Groenendyk, J.; Michalak, M. Calreticulin Signaling in Health and Disease. Int. J. Biochem. Cell Biol. 2012, 44, 842-846. [CrossRef]

85. Yan, X.; Yu, H.; Liu, Y.; Hou, J.; Yang, Q.; Zhao, Y. MiR-27a-3p Functions as a Tumor Suppressor and Regulates Non-Small Cell Lung Cancer Cell Proliferation via Targeting HOXB8. Technol. Cancer Res. Treat. 2019, 18, 1533033819861971. [CrossRef]

86. Tang, H.; Xu, X.; Xiao, W.; Liao, Y.; Xiao, X.; Li, L.; Li, K.; Jia, X.; Feng, H. Silencing of MicroRNA-27a Facilitates Autophagy and Apoptosis of Melanoma Cells through the Activation of the SYK-Dependent MTOR Signaling Pathway. J. Cell. Biochem. 2019, 120, 13262-13274. [CrossRef] 
87. Li, J.-M.; Zhou, J.; Xu, Z.; Huang, H.-J.; Chen, M.-J.; Ji, J.-S. MicroRNA-27a-3p Inhibits Cell Viability and Migration through down-Regulating DUSP16 in Hepatocellular Carcinoma. J. Cell. Biochem. 2018, 119, 5143-5152. [CrossRef]

88. Xu, C.; Cheng, H.; Li, N.; Zhou, N.; Tang, X. Relationship between MicroRNA-27a and Efficacy of Neoadjuvant Chemotherapy in Gastric Cancer and Its Mechanism in Gastric Cancer Cell Growth and Metastasis. Biosci. Rep. 2019, 39. [CrossRef]

89. Mu, Y.; Zhang, L.; Chen, X.; Chen, S.; Shi, Y.; Li, J. Silencing MicroRNA-27a Inhibits Proliferation and Invasion of Human Osteosarcoma Cells through the SFRP1-Dependent Wnt/ $\beta$-Catenin Signaling Pathway. Biosci. Rep. 2019, 39. [CrossRef] [PubMed]

90. Ciocca, D.R.; Calderwood, S.K. Heat Shock Proteins in Cancer: Diagnostic, Prognostic, Predictive, and Treatment Implications. Cell Stress Chaperones 2005, 10, 86-103. [CrossRef]

91. Binder, R.J. Functions of Heat Shock Proteins in Pathways of the Innate and Adaptive Immune System. J. Immunol. 2014, 193, 5765-5771. [CrossRef] [PubMed]

92. Garrido, C.; Gurbuxani, S.; Ravagnan, L.; Kroemer, G. Heat Shock Proteins: Endogenous Modulators of Apoptotic Cell Death. Biochem. Biophys. Res. Commun. 2001, 286, 433-442. [CrossRef]

93. Rodríguez, M.E.; Cogno, I.S.; Milla Sanabria, L.S.; Morán, Y.S.; Rivarola, V.A. Heat Shock Proteins in the Context of Photodynamic Therapy: Autophagy, Apoptosis and Immunogenic Cell Death. Photochem. Photobiol. Sci. Off. J. Eur. Photochem. Assoc. Eur. Soc. Photobiol. 2016, 15, 1090-1102. [CrossRef]

94. He, S.-J.; Cheng, J.; Feng, X.; Yu, Y.; Tian, L.; Huang, Q. The Dual Role and Therapeutic Potential of High-Mobility Group Box 1 in Cancer. Oncotarget 2017, 8, 64534-64550. [CrossRef] [PubMed]

95. Kang, R.; Zhang, Q.; Zeh, H.J.; Lotze, M.T.; Tang, D. HMGB1 in Cancer: Good, Bad, or Both? Clin. Cancer Res. Off. J. Am. Assoc. Cancer Res. 2013, 19, 4046-4057. [CrossRef]

96. Liu, L.; Ren, W.; Chen, K. MiR-34a Promotes Apoptosis and Inhibits Autophagy by Targeting HMGB1 in Acute Myeloid Leukemia Cells. Cell. Physiol. Biochem. 2017, 41, 1981-1992. [CrossRef]

97. Ratti, M.; Lampis, A.; Ghidini, M.; Salati, M.; Mirchev, M.B.; Valeri, N.; Hahne, J.C. MicroRNAs (MiRNAs) and Long Non-Coding RNAs (LncRNAs) as New Tools for Cancer Therapy: First Steps from Bench to Bedside. Target. Oncol. 2020, 15, 261-278. [CrossRef]

98. Acunzo, M.; Romano, G.; Wernicke, D.; Croce, C.M. MicroRNA and Cancer-a Brief Overview. Adv. Biol. Regul. 2015, 57, 1-9. [CrossRef]

99. Yang, L.; Yu, Y.; Kang, R.; Yang, M.; Xie, M.; Wang, Z.; Tang, D.; Zhao, M.; Liu, L.; Zhang, H.; et al. Up-Regulated Autophagy by Endogenous High Mobility Group Box-1 Promotes Chemoresistance in Leukemia Cells. Leuk. Lymphoma 2012, 53, 315-322. [CrossRef] [PubMed]

100. Costa, D.F.; Torchilin, V.P. Micelle-like Nanoparticles as SiRNA and MiRNA Carriers for Cancer Therapy. Biomed. Microdevices 2018, 20, 59. [CrossRef] [PubMed]

101. Phung, C.D.; Nguyen, H.T.; Choi, J.Y.; Pham, T.T.; Acharya, S.; Timilshina, M.; Chang, J.-H.; Kim, J.-H.; Jeong, J.-H.; Ku, S.K.; et al. Reprogramming the T Cell Response to Cancer by Simultaneous, Nanoparticle-Mediated PD-L1 Inhibition and Immunogenic Cell Death. J. Control. Release 2019, 315, 126-138. [CrossRef] [PubMed]

102. Harris, J.M.; Chess, R.B. Effect of Pegylation on Pharmaceuticals. Nat. Rev. Drug Discov. 2003, 2, 214-221. [CrossRef]

103. Zwicke, G.L.; Mansoori, G.A.; Jeffery, C.J. Utilizing the Folate Receptor for Active Targeting of Cancer Nanotherapeutics. Nano Rev. 2012, 3, 18496. [CrossRef] [PubMed]

104. Wang, L.; Liang, T.-T. CD59 Receptor Targeted Delivery of MiRNA-1284 and Cisplatin-Loaded Liposomes for Effective Therapeutic Efficacy against Cervical Cancer Cells. AMB Express 2020, 10, 54. [CrossRef]

105. Afshar-Kharghan, V. The Role of the Complement System in Cancer. J. Clin. Investig. 2017, 127, 780-789. [CrossRef] [PubMed]

106. Unlu, S.; Tang, S.; Na Wang, E.; Martinez, I.; Tang, D.; Bianchi, M.E.; Iii, H.J.Z.; Lotze, M.T. Damage Associated Molecular Pattern Molecule-Induced MicroRNAs (DAMPmiRs) in Human Peripheral Blood Mononuclear Cells. PLoS ONE 2012, 7, e38899. [CrossRef]

107. Frank, A.C.; Ebersberger, S.; Fink, A.F.; Lampe, S.; Weigert, A.; Schmid, T.; Ebersberger, I.; Syed, S.N.; Brüne, B. Apoptotic Tumor Cell-Derived MicroRNA-375 Uses CD36 to Alter the Tumor-Associated Macrophage Phenotype. Nat. Commun. 2019, $10,1135$. [CrossRef]

108. Fabbri, M.; Paone, A.; Calore, F.; Galli, R.; Gaudio, E.; Santhanam, R.; Lovat, F.; Fadda, P.; Mao, C.; Nuovo, G.J.; et al. MicroRNAs Bind to Toll-like Receptors to Induce Prometastatic Inflammatory Response. Proc. Natl. Acad. Sci. USA 2012, 109, E2110-E2116. [CrossRef]

109. Lee, J.; Lee, Y.; Xu, L.; White, R.; Sullenger, B.A. Differential Induction of Immunogenic Cell Death and Interferon Expression in Cancer Cells by Structured SsRNAs. Mol. Ther. J. Am. Soc. Gene Ther. 2017, 25, 1295-1305. [CrossRef]

110. Ogino, S.; Nowak, J.A.; Hamada, T.; Phipps, A.I.; Peters, U.; Milner, D.A.; Giovannucci, E.L.; Nishihara, R.; Giannakis, M.; Garrett, W.S.; et al. Integrative Analysis of Exogenous, Endogenous, Tumour and Immune Factors for Precision Medicine. Gut 2018, 67, 1168-1180. [CrossRef] [PubMed]

111. Ogino, S.; Nowak, J.A.; Hamada, T.; Milner, D.A.; Nishihara, R. Insights into Pathogenic Interactions Among Environment, Host, and Tumor at the Crossroads of Molecular Pathology and Epidemiology. Annu. Rev. Pathol. 2019, 14, 83-103. [CrossRef] 